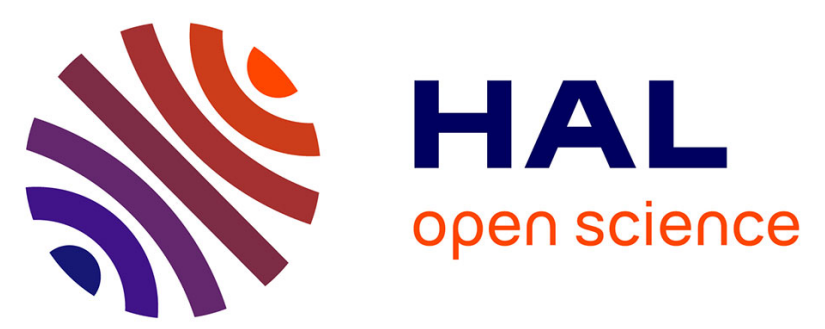

\title{
On the importance of combining bulk- and surface-active sites to maximize the catalytic activity of metal-organic frameworks for the oxidative dehydrogenation of alcohols using alkyl hydroperoxides as hydride acceptors
}

P. Gairola, Y. Millot, J.-M. Krafft, F. Averseng, Franck Launay, P. Massiani, C. Jolivalt, J. Reboul

\section{To cite this version:}

P. Gairola, Y. Millot, J.-M. Krafft, F. Averseng, Franck Launay, et al.. On the importance of combining bulk- and surface-active sites to maximize the catalytic activity of metal-organic frameworks for the oxidative dehydrogenation of alcohols using alkyl hydroperoxides as hydride acceptors. Catalysis Science \& Technology, 2020, 10 (20), pp.6935-6947. 10.1039/D0CY00901F . hal-03089746

\author{
HAL Id: hal-03089746 \\ https://hal.science/hal-03089746
}

Submitted on 6 Jan 2021

HAL is a multi-disciplinary open access archive for the deposit and dissemination of scientific research documents, whether they are published or not. The documents may come from teaching and research institutions in France or abroad, or from public or private research centers.
L'archive ouverte pluridisciplinaire HAL, est destinée au dépôt et à la diffusion de documents scientifiques de niveau recherche, publiés ou non, émanant des établissements d'enseignement et de recherche français ou étrangers, des laboratoires publics ou privés. 


\title{
On the importance of combining bulk-and surface-active sites to maximize the catalytic activity of metal-organic frameworks for the oxidative dehydrogenation of alcohols using alkyl hydroperoxides as hydride acceptors
}

\author{
P. Gairola, Y. Millot, J-M. Krafft, F. Averseng, F. Launay, P. Massiani, C. Jolivalt, J. Reboul*
}

Sorbonne Université, Campus UPMC, CNRS UMR-7197, Laboratoire de Réactivité de Surface, 4 Place Jussieu, 75005 Paris, France

Corresponding author: julien.reboul@sorbonne-universite.fr

Keywords: bulk and surface uncoordinated zirconium, FT-IR spectroscopy of adsorbed CO, solid-state ${ }^{1} \mathrm{H}$ NMR, oxidative alcohol dehydrogenation, alkylhydroperoxide as hydride acceptor.

\begin{abstract}
A series of zirconium-terephthalate UiO-66 metal-organic frameworks (MOF) containing partially uncoordinated zirconium sites $\left(\mathrm{Zr}_{\mathrm{UC}}\right)$ was synthesized, finely characterized by complementary physico-chemical techniques, and employed to catalyze the oxidative dehydrogenation of alcohols in the presence of tert-butyl hydroperoxide (TBHP). These sites were twofold: bulk $\mathrm{Zr}_{\mathrm{UC}}$ sites created by reducing the content of terephthalate linkers within the framework and intrinsic $\mathrm{Zr}_{\mathrm{UC}}$ sites existing on the external surface of undefective UiO-66 crystals. Activity of both sites was evidenced by the linear dependency taking place between activity and either missing linkers or external surface area. Combining in one UiO-66 crystal a high density of $\mathrm{Zr}_{\mathrm{UC}}$ sites within the bulk and a high external surface area enabled to maximize the performances of the catalysts in alcohol dehydrogenation, making possible an oxidation of benzyl alcohol over $90 \%$ under mild temperature $\left(\mathrm{T}=40^{\circ} \mathrm{C}\right)$ after $2 \mathrm{~h}$ of reaction. More challenging secondary alcohols were also oxidized. The formation of Lewis acid sites at the inorganic nodes was followed by FTIR spectroscopy of adsorbed CO. The presence of bulk and/or external $\mathrm{Zr}_{\mathrm{UC}}$ sites was further disclosed by the observation on hydrated samples of solid-state ${ }^{1} \mathrm{H}$ NMR signals, corresponding to the proton of terminal $\mu_{1}-\mathrm{OH}$ moieties capping the $\mathrm{Zr}_{\mathrm{UC}}$ sites. Interestingly, two distinct NMR signals corresponding to the terminal $\mu_{1}-\mathrm{OH}$ moieties of bulk and surface $\mathrm{Zr}_{\mathrm{UC}}$ sites were identified. Finally, a mechanism of alcohol dehydrogenation using TBHP was proposed relying on the concomitant coordination of benzyl alcohol and TBHP onto the two adjacent $\mathrm{Zr}_{\mathrm{UC}}$ sites at the zirconium cornerstones.
\end{abstract}

\section{Introduction.}

Oxidation of alcohols is a critical step for the production of high value fine chemical intermediates towards the development of new products in various major industrial sectors, such as the pharmaceutical, agronomical, food and flavor ones. ${ }^{1,2}$ Alcohol oxidation is also of great importance in the transformation of biomass-derived molecules. However, this reaction is generally achieved with stoichiometric amount 
of relatively expensive and toxic chemicals (chromium oxide, potassium dichromate and potassium permanganate) producing high quantity of toxic wastes. During the last decades, research has been focused to develop more efficient means to oxidize alcohols, particularly on the development of new transition metal complexes to catalyze the oxidation of alcohols by inexpensive and environmentally compatible oxidants such as hydrogen peroxide or molecular oxygen.

Oxidation of alcohols based on hydrogen-transfer, such as the Oppenauer oxidation, is an interesting alternative to redox-catalyzed processes. This type of oxidation utilizes relatively inexpensive and safe catalysts, such as titanium and zirconium based-Lewis acid (often aluminum or zirconium alkoxide $\left.\left(\mathrm{M}(\mathrm{OR})_{4}\right)\right)$ and cheap aldehydes, or ketones as hydrogen acceptor. ${ }^{3}$ Besides, Krohn and collaborators have reported the employment of alkyl hydroperoxides (tert-butylhydroperoxide (TBHP) or cumyl hydroperoxide (CHP)) as an alternative to aldehydes and ketones. ${ }^{4}$ With TBHP, the transfer of the $\alpha-$ hydride from the alcohol to the peroxo O-O bond of the hydroperoxide activated by its coordination to a zirconium center, i.e. zirconium isopropoxide $\left(\mathrm{Zr}(\mathrm{OiPr})_{4}\right)$, leads to the alcohol oxidation product, either ketone or aldehyde, and tert-butanol. Compared to the classic Oppenauer reaction, the use of TBHP as hydride acceptor presents several advantages. Firstly, whereas in the Oppenauer oxidation the equilibrium is determined by the redox potential of the two carbonyl/alcohol pairs, the hydride transfer to the $\mathrm{O}-\mathrm{O}$ acceptor is essentially irreversible and can therefore be quantitative provided that the process is kinetically possible. Secondly, since the $\mathrm{H}$-acceptor ability of alkyl hydroperoxides is stronger than that of aldehyde or ketones, the reaction can proceed under mild temperature conditions with substoichiometric amount of metal catalysts. Third, high reaction rates enabled by using a strong $\mathrm{H}$ acceptor such as TBHP, limits the side reactions such as aldol condensation and Tishchenko reaction. ${ }^{5}$ Despite of the above mentioned advantages, the use of an alkyl hydroperoxide as $\mathrm{H}$-acceptor in such type of oxidation was only scarcely studied. ${ }^{4,6,7}$

Herein, we report the application of a zirconium-based Metal-Organic Framework (UiO-66) containing structural defects as a new heterogeneous catalyst for alcohol dehydrogenation using TBHP as $\mathrm{H}$-acceptor. UiO-66 is a highly porous $\mathrm{MOF}\left(\mathrm{Zr}_{6} \mathrm{O}_{4}(\mathrm{OH})_{4} \mathrm{BDC}_{6}\right)$ made of $\mathrm{Zr}_{6} \mathrm{O}_{4}(\mathrm{OH})_{4}$ octahedron inorganic nodes connected to one another by 1,4-benzenedicarboxylate (BDC, or terephthalate) linkers (Figure 1A). Owing to its exceptional stability, this MOF can be synthesized with a deficiency of BDCs without affecting its structural integrity. These missing linkers, in particular missing carboxylate functions, are known to create defective sites at the inorganic cornerstones as pairs of adjacent undercoordinated zirconium sites $\mathrm{Zr}-\mathrm{OH}-\mathrm{Zr}$ (labelled $B-\mathrm{Zr}_{U C}$ in the following). The Lewis acid character of these sites was recently found to generate activity for the catalysis of reactions such as aldol condensation, ${ }^{8}$ aldehyde acetalization, ${ }^{9} \mathrm{CO}_{2}$ fixation, ${ }^{10}$ and Oppenauer oxidation. ${ }^{11}$ In addition to these bulk $\mathrm{Zr}_{\mathrm{UC}}$ sites, other under-coordinated $\mathrm{Zr}_{\mathrm{UC}}$ pairs are expected to intrinsically exist on the external surface of the UiO-66 crystals (labelled $E S-\mathrm{Zr}_{\mathrm{UC}}$ ) because MOF crystal growth terminates either with pending organic linkers or with uncoordinated metals. ${ }^{12}$ These surface open metal sites has also already been exploited as catalysts. ${ }^{13}$ Both types of sites, $\mathrm{B}-\mathrm{Zr}_{\mathrm{UC}}$ and $\mathrm{ES}-\mathrm{Zr}_{\mathrm{UC}}$, have distinct structural locations, 
as represented in Scheme 1A, however they are chemically similar, as illustrated in Figure 1B where a pair of $\mathrm{Zr}_{\mathrm{UC}}$ sites, bearing a delocalized negative charge due to the missing carboxylate function, is caped with one terminal hydroxy group (labeled $\mu_{l^{-}} \mathrm{OH}$ ) and one water molecule, as it occurs under ambient hydrated atmosphere; the bridging hydroxy group existing as well in hydrated conditions is also represented (labeled $\left.\mu_{3}-\mathrm{OH}\right)$. Noteworthy, the coexistence of the Lewis acid character $\left(\mathrm{Zr}_{\mathrm{UC}}\right)$ and Brønsted acid/basic sites $\left(\mu_{1}-\mathrm{OH}\right.$ and $\left.\mu_{3}-\mathrm{OH}\right)$ is at the origin of the catalytic activity of these hydrated sites. ${ }^{11}$
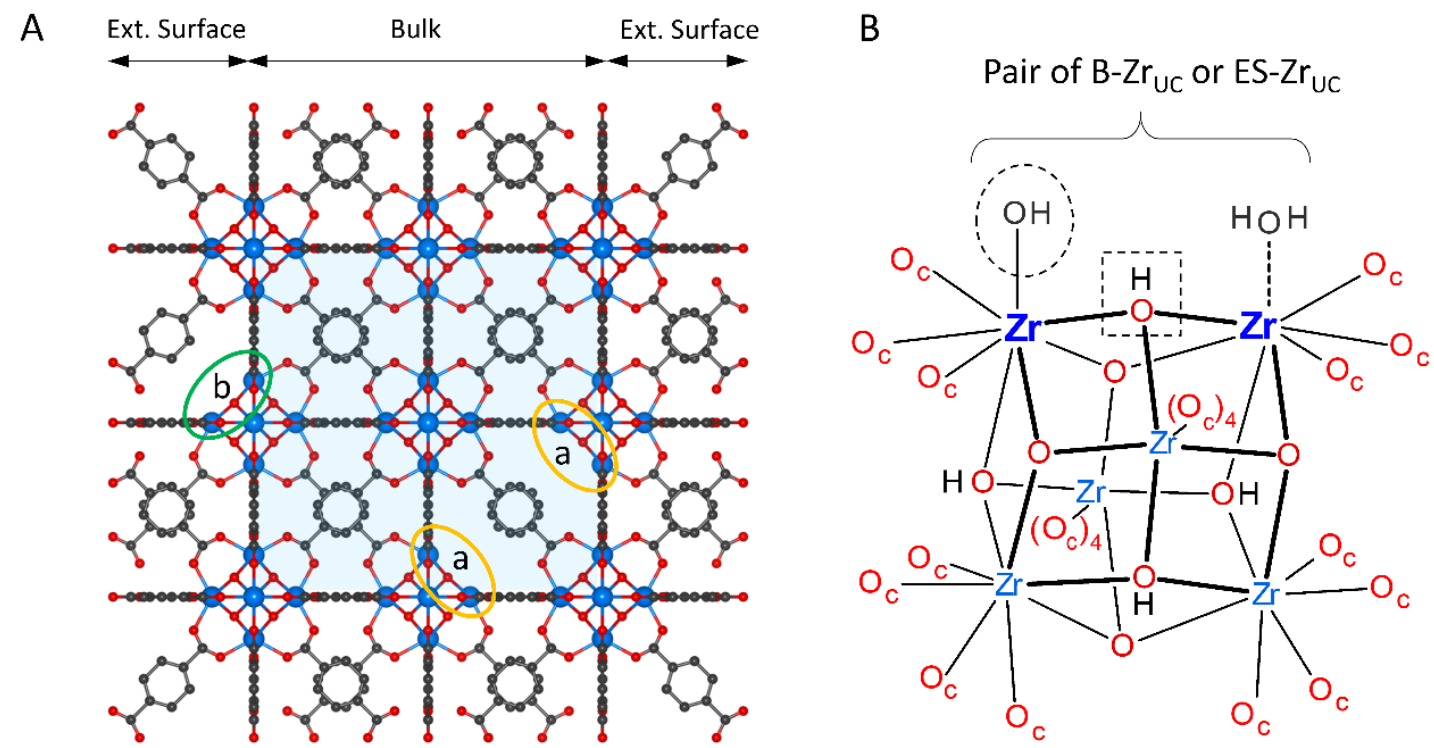

Figure 1. (A) Schematic representation of a UiO-66 crystal containing (a) two pairs of B-Zr $\mathrm{r}_{\mathrm{UC}}$ sites (surrounded by a yellow line) and (b) a pair of ES-Zr $\mathrm{ZrC}_{\mathrm{UC}}$ sites on the external surface (surrounded by a green line); both types of pairs are due to one missing linker (B) Schematic representation of a defective hydrated $\mathrm{Zr}_{6}$ node displaying a pair of $\mathrm{Zr}_{\mathrm{UC}}$ sites (noted in bold and dark blue color) caped with one water molecule and one hydroxy group (terminal $\mu_{1}-\mathrm{OH}$, dashed circle); the bridging $\mu_{3}-\mathrm{OH}$ group is also shown (dashed square). In A and B, zirconium, oxygen and carbon atoms appear as blue, red and dark grey spheres, respectively. In (A) hydrogen atoms are omitted for clarity and the part of the scheme representing the bulk of the UiO-66 crystal is colored in light blue. In (B), oxygen atoms of carboxylate functions are shown as $\mathrm{O}_{c}$.

In this study, two series of UiO-66 samples were prepared by systematically varying the densities of $\mathrm{B}-\mathrm{Zr}_{\mathrm{UC}}$ and $\mathrm{ES}-\mathrm{Zr}_{\mathrm{UC}}$ pairs in an independent fashion in order to (i) evidence their existence, (ii) confirm the role of each type of site in the alcohol oxidation catalysis and (iii) set a synthesis procedure to optimize the UiO-66 performances (to combine high densities of both $\mathrm{Zr}_{\mathrm{UC}}$ sites in the same crystal). All samples were characterized with respect to their structure, porosity, crystal sizes and linker contents. The $\mathrm{Zr}_{\mathrm{UC}}$ pairs, in their non-hydrated and hydrated states, were characterized by spectroscopic techniques. Their activity for benzyl alcohol oxidation in mild conditions $\left(\mathrm{T}=40^{\circ} \mathrm{C}\right)$ in presence of TBHP was evaluated. Based on the catalytic results, a reaction mechanism is finally proposed. 


\section{Experimental and methods.}

\section{Materials}

The reagents, anhydrous zirconium chloride, zirconyl chloride octahydrate, tert-butyl hydroperoxide, 1 , 4-bezenedicarboxylic acid, 37\% hydrochloric acid, 2-hexanone, menthol, and butylated hydroxytoluene were purchased from Sigma Aldrich. N,N-dimethyformaldehyde was purchased from Prolabo VWR and benzyl alcohol was bought from Merck. Acetonitrile was purchased from Alfa aesar. All the chemicals were used as received unless otherwise mentioned.

\section{Synthesis of UiO-66}

The UiO-66 materials were synthesized by adapting the standard protocol reported previously. ${ }^{14}$ Briefly, $1.13 \mathrm{~g}(4.85 \mathrm{mmol})$ of $\mathrm{ZrCl}_{4}$ and $1.61 \mathrm{~g}(9.70 \mathrm{mmol})$ of $\mathrm{BDC}$ (corresponding to a BDC/Zr molar ratio of 2) were introduced in a $100 \mathrm{~mL}$ Teflon flask followed by the addition of $29.1 \mathrm{~mL}$ DMF and $0.808 \mathrm{~mL}$ of $37 \mathrm{wt} . \% \mathrm{HCl}$. After allowing the solution to homogenize for $1 \mathrm{~h}$ under constant stirring at room temperature, the Teflon flask was sealed in a stainless-steel autoclave and heated to $160^{\circ} \mathrm{C}$ for $20 \mathrm{~h}$. The white solid was then recovered by vacuum filtration, washed 3 times with DMF at $120{ }^{\circ} \mathrm{C}$ for $6 \mathrm{~h}$ followed by 2 times with ethanol at $80^{\circ} \mathrm{C}$ for $6 \mathrm{~h}$ (and separated each time by vacuum filtration). After drying in an oven set to $80^{\circ} \mathrm{C}$ for $1 \mathrm{~h}$, the product was activated in static air for $20 \mathrm{~h}$ at $200{ }^{\circ} \mathrm{C}$.

The series of undefective UiO-66 with various crystals sizes was prepared following the above standard protocol (with constant $\mathrm{BDC} / \mathrm{Zr}$ molar ratio of 2) but employing zirconium precursors with different hydration degrees $\left(\mathrm{H}_{2} \mathrm{O} / \mathrm{Zr}\right.$ molar ratios $=0,4,6$, and 9) obtained by mechanical mixing of $\mathrm{ZrCl}_{4}$ and four given amounts of water in a mortar for $10 \mathrm{~min}$. For the defective UiO-66 crystals possessing different numbers of missing organic linkers per $\mathrm{Zr}_{6}$ formula unit, the zirconium precursor was kept dehydrated $\left(\mathrm{H}_{2} \mathrm{O} / \mathrm{Zr}\right.$ molar ratio $\left.=0\right)$ but the $\mathrm{BDC} / \mathrm{Zr}$ ratio was decreased to 1 or 0.5 (instead of 2). The obtained UiO-66 samples are labelled UiO- $\mathrm{x}-\mathrm{y}$ where $\mathrm{x}$ refers to the nominal $\mathrm{Zr} / \mathrm{BDC}$ molar ratio $(\mathrm{x}=$ 2, 1 and 0.5) and y corresponds to the $\mathrm{H}_{2} \mathrm{O} / \mathrm{Zr}$ molar ratio ( $\mathrm{y}=0,4,6$ and 9). Note that a UiO-1-9 material displaying both small crystals and missing linkers was also synthesized to study the combined effect of a high external specific surface area and relatively large number of missing linkers.

\section{Catalytic Tests}

The oxidation of benzyl alcohol was carried out in a test tube maintained at $40{ }^{\circ} \mathrm{C}$ using an oil bath. Briefly, $13 \mu \mathrm{L}$ benzyl alcohol $(0.125 \mathrm{mmol})$ and $15.5 \mu \mathrm{L}$ 2-hexanone $(0.125 \mathrm{mmol})$ used as internal standard, were dissolved in $0.5 \mathrm{~mL}$ of acetonitrile. Then, $30 \mathrm{mg}$ of catalyst, previously activated overnight at $80^{\circ} \mathrm{C}$ under vacuum, was added followed by the addition of $45.5 \mu \mathrm{L}$ TBHP $(0.250 \mathrm{mmol})$. The reaction mixture was magnetically stirred at $200 \mathrm{rpm}$ for $31 \mathrm{~h} .10 \mu \mathrm{L}$ of aliquot was taken from the reaction mixture every $1 \mathrm{~h}$ during $5 \mathrm{~h}$ and the last one after $22 \mathrm{~h}$ or $31 \mathrm{~h}$ and analyzed by gas chromatography. Experiments were repeated three times and standard deviation $(\sigma=4.5)$ was determined. 


\section{Instrumentation and measurements}

Laboratory X-ray diffraction (XRD) patterns were recorded using a Bruker D8 Advance diffractometer equipped with a copper source $(\lambda \mathrm{CuK} \alpha 1=1.54056 \AA, \lambda \mathrm{Cu}-\mathrm{K} \alpha 2=1.54439 \AA)$ and a LynxEye detector. XRD patterns were recorded by steps in $2 \theta$ range of $4-40^{\circ}$. Thermogravimetric experiments were performed on a STD Q600 apparatus with $20 \mathrm{~mL} \cdot \mathrm{min}^{-1}$ of air and a ramp of $5{ }^{\circ} \mathrm{C} \cdot \mathrm{min}^{-1}$ up to $1000{ }^{\circ} \mathrm{C}$. Textural properties of the materials were determined by dinitrogen $\left(\mathrm{N}_{2}\right)$ sorption performed on a Belsorp-max apparatus after outgassing the samples at $120^{\circ} \mathrm{C}$ overnight. Total specific surface area and external specific surface area were determined by the BET method. Pore volumes were determined by applying the t-plot method.

Electron spin resonance (ESR) measurements were performed on a JEOL FA300 computerized spectrometer working at $\sim 9.3 \mathrm{GHz}$ (X-band). The presented spectra were recorded either at room temperature or at $-196{ }^{\circ} \mathrm{C}$, using an insertion dewar containing liquid nitrogen. A microwave power of $2 \mathrm{~mW}$ and $100 \mathrm{kHz}$ field modulation were applied. Computer simulations of the spectra were performed using the EPR sim32 program.

Transmission infrared (FTIR) spectra of adsorbed CO were collected on a Bruker Vertex 70 spectrometer using a MCT detector (resolution $2 \mathrm{~cm}^{-1}, 128$ scans per spectrum). The sample was supported on a gold grid $(10 \mathrm{~mm} \times 10 \mathrm{~mm}$ ) equipped with a magnet (for sample mobility). It was placed in a glass cell consisting of two parts for pretreatments (heated upper part) and FTIR measurements (lower part, placed in the IR beam) and of a trap maintained at liquid $\mathrm{N}_{2}$ temperature to condense all eventual water molecules present in the cell. Each experiment was done as follows: the sample was first placed in the upper part of the cell and heated at $200{ }^{\circ} \mathrm{C}$ (heating rate $2{ }^{\circ} \mathrm{C} \cdot \mathrm{min}^{-1}$ ) for $2 \mathrm{~h}$ under flowing argon then for $1 \mathrm{~h}$ at a residual pressure of $\sim 1 \times 10^{-4} \mathrm{~Pa}$; it was next transferred to the lower part of the cell (placed at $\sim-173{ }^{\circ} \mathrm{C}$ ) where $\mathrm{CO}$ was introduced gradually till the pressure of 1 Torr is reached, followed by a slow and dynamic evacuation for $40 \mathrm{~min}$ and a spectrum was recorded. The sample was next transferred again to the upper part of the tube with the help of the magnet, heated at $300{ }^{\circ} \mathrm{C}$, transferred back to the lower part (still maintained at - $173^{\circ} \mathrm{C}$ ), and a second spectrum was registered. Rehydrated spectra were collected on samples kept under static vacuum ( 10-6 mbar) at room temperature after the treatment at $300^{\circ} \mathrm{C}$ under argon, subsequent $\mathrm{CO}$ adsorption at $-173{ }^{\circ} \mathrm{C}$ and a final evacuation (CO desorption) step. All spectra were plotted after subtraction of the spectrum of the pure CO gas phase.

Solid state magic angle spinning nuclear magnetic resonance (MAS NMR) experiments were performed on a Bruker AVANCE500 spectrometer at $11.7 \mathrm{~T}$ in $2.5 \mathrm{~mm}$ zirconia rotors spun at $30 \mathrm{kHz}$. The resonance frequency of ${ }^{1} \mathrm{H}$ was $500.16 \mathrm{MHz}$. Chemical shifts, $\delta$, were reported relative to adamantane powder (38.52 ppm). Measurements were performed at varying humidity degree as follows: the sample was dehydrated for $5 \mathrm{~min}$ at $300{ }^{\circ} \mathrm{C}$ under a flow of dry argon and placed in a zirconia NMR rotor (still under a dry argon atmosphere, in a glove box). The rotor was then opened for a given time and 
transferred into the magnet after being closed, rotated and a ${ }^{1} \mathrm{H}$ MAS NMR spectrum was collected. The rotor was then opened again for a given time, closed, rotated again, and another spectrum was collected. By repeating the procedure, a series of spectra was collected at regular times for $5 \mathrm{~h}$ corresponding to increasing rehydration durations. The relative humidity in the experimental room was approximately $30 \%$.

For catalytic tests, products analysis was performed using a Perichrom PR2100 gas chromatography equipped with a FID detector $\left(250^{\circ} \mathrm{C}\right)$ and a BP5 column (30 m length, $0.5 \mathrm{~mm}$ diameter).

\section{Results and discussion.}

\section{Physicochemical characteristics of the UiO-66 series of materials (UiO-x-y).}

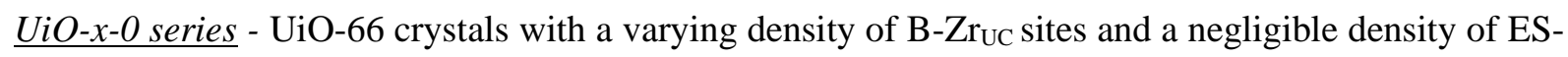
$\mathrm{Zr}_{\mathrm{UC}}$ (the UiO-x-0 series) were first synthesized by using a constant amount of dehydrated $\mathrm{Zr}$ precursor $\left(\mathrm{ZrCl}_{4}\right)$ but distinct BDC contents $(\mathrm{x}=\mathrm{BDC} / \mathrm{Zr}=2,1$ and 0.5$)$. The three samples exhibited identical XRD patterns typical of the UiO-66 structure (Figure 2A, patterns a to c). The content of organic linker in these materials was determined by thermogravimetric analysis (carried out in air) based on the weight loss occurring at $400^{\circ} \mathrm{C}$ (Figure $2 \mathrm{~B}$, curves a to c). This gave the number of missing linkers per $\mathrm{Zr}_{6}$ formula unit by following the calculation method reported by Shearer and al. ${ }^{14}$ (Supporting information discussion S1). The obtained values (Table 1) indicate that an excess of BDCs relative to the zirconium source in the synthesis medium $(\mathrm{BCD} / \mathrm{Zr}=2)$ results in an undefective material (UiO-2-0), while the lower BDC contents give defective UiO-66 materials with 0.5 (UiO-1-0) and 2.5 (UiO-0.5-0) missing linkers per $\mathrm{Zr}_{6}$ formula unit. The impact of these structural defects on porous characteristics is depicted in Figure 2C (isotherms a to c). A similar type-I shape is observed for the $\mathrm{N}_{2}$ isotherms of the three samples. However, these isotherms reveal distinct adsorption capacities, detailed in Table 1. The surface area of c.a. $1150 \mathrm{~m}^{2} . \mathrm{g}^{-1}$ and total pore volume of $0.5 \mathrm{~cm}^{3} \cdot \mathrm{g}^{-1}$ for undefective UiO-2-0 are in the range of values reported in the literature for UiO-66 with a defect-free structure. ${ }^{14,15}$ These values increase in both UiO-1-0 and UiO-0.5-0, in agreement with the expected creation of an additional porosity in UiO66 frameworks where part of the organic linkers is missing. ${ }^{16}$ The effect is particularly high for UiO0.5-0, in which the micropore volume determined by t-plot method is close to 1.5 times higher than that in UiO-2-0 (Table 1). Such high porosity increase in UiO-0.5-0 might be due to the occurrence of defects generated by missing clusters in addition to those formed from missing linkers, similar to the case reported by Lingmei Liu and co-workers. ${ }^{17}$ This assumption is supported by the fact that the volume of adsorbed $\mathrm{N}_{2}$ at saturation for this sample $\left(\mathrm{V}=490 \mathrm{~cm}^{3} \cdot \mathrm{g}^{-1}\right.$ at $\left.\mathrm{P} / \mathrm{P}_{0}=0.2\right)$ is both higher than that expected for a material with maximum possible amount of defects determined by Shearer et al. ( $\mathrm{V}=330 \mathrm{~cm}^{3} \cdot \mathrm{g}^{-1}$ at $\mathrm{P} / \mathrm{P}_{0}=0.2$ ) and close to that of the saturated volume of adsorbed $\mathrm{N}_{2}$ modeled by the same group for UiO-66 containing cluster defects with a pure reo topology (the topology of the UiO-66 containing the highest possible number of cluster defects, $\mathrm{V}=450 \mathrm{~cm}^{3} \cdot \mathrm{g}^{-1}$ at $\left.\mathrm{P} / \mathrm{P}_{0}=0.2\right) .{ }^{16}$ Noteworthy, the three 
materials possess similar low external surface areas (Table 1), suggesting a limited effect of the initial $\mathrm{Zr} / \mathrm{BDC}$ molar ratio on the crystal size and a low amount of external ES- $\mathrm{Zr}_{\mathrm{UC}}$ sites.
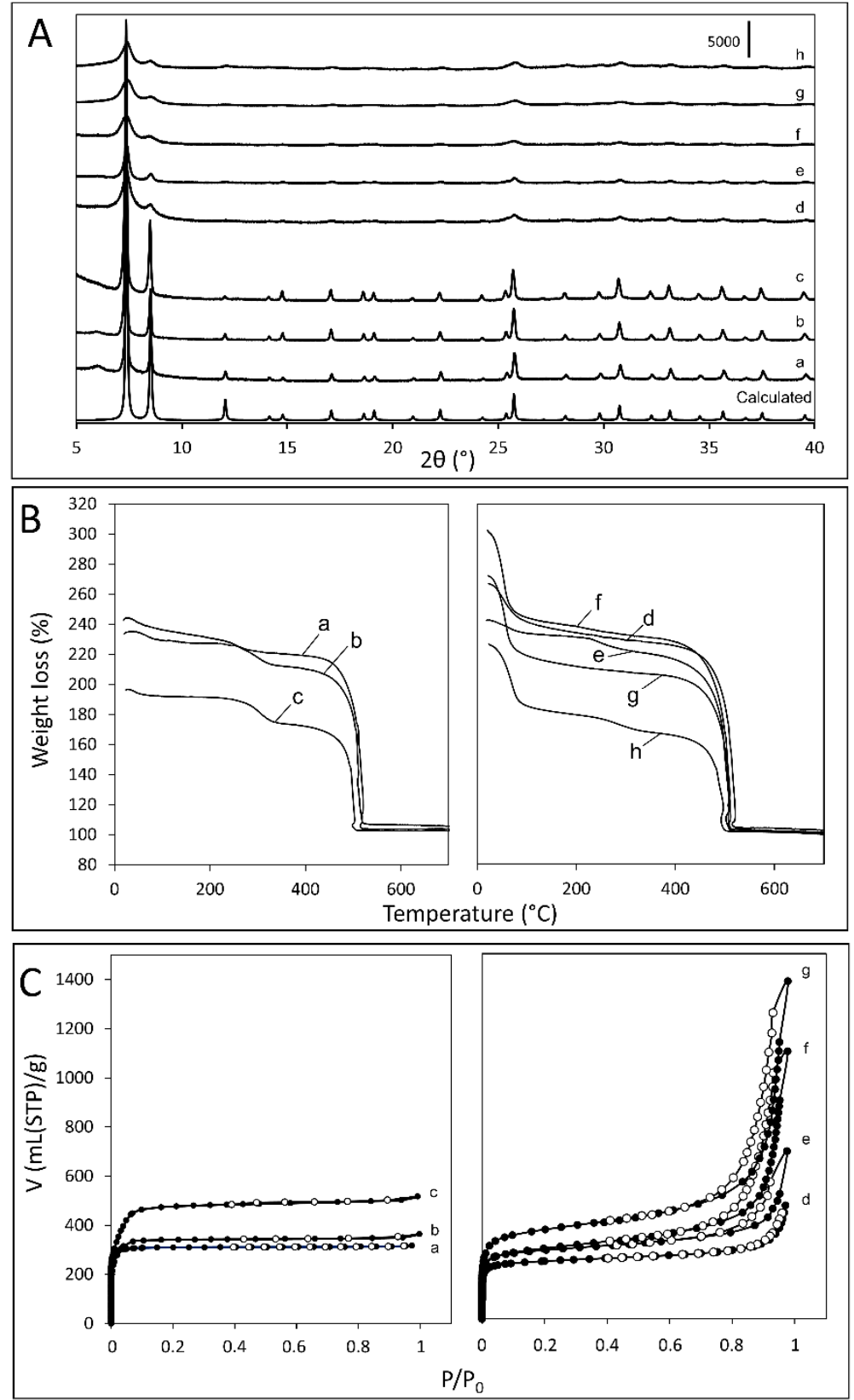

Figure 2. Characterization by (A) powder X-ray diffraction, (B) thermogravimetric analysis and (C) $\mathrm{N}_{2}$ sorption of samples (a) UiO-2-0, (b) UiO-1-0 and (c) UiO-0.5-0 containing varying missing organic ligand densities, and (d) UiO-2-4, (e) UiO-2-6 and (f) UiO-2-9 synthetized with $\mathrm{ZrCl}_{4}$ precursors of varying degrees of hydration. The data for samples (g) UiO-1-9 and (h) UiO-0.5-9 are also represented. The calculated diffractogram for undefective UiO-66 is shown in (A). The end weight of the TGA run was normalized to $100 \%$ in order to calculate the number of missing linkers in each sample (See Supporting Information for calculation details). 
$\underline{\text { UiO-2-y series }}$ - The second UiO-66 series (UiO-2-y) consists of samples made of undefective crystals (constant BDC content, $\mathrm{x}=2$ ) but having varying crystal sizes and hence varying $\mathrm{ES}-\mathrm{Zr}_{\mathrm{UC}}$ sites densities. This was achieved by modulating the hydration degree of the $\mathrm{ZrCl}_{4}$ zirconium precursor used for the synthesis $\left(\mathrm{y}=\mathrm{H}_{2} \mathrm{O} / \mathrm{Zr}=0,4,6\right.$, and 9). This strategy was inspired by a previous report showing that employing $\mathrm{ZrOCl}_{2} .8 \mathrm{H}_{2} \mathrm{O}$ instead of anhydrous $\mathrm{ZrCl}_{4}$ as $\mathrm{Zr}$ precursor for the synthesis of UiO-66 results in a drastic reduction of the crystal size due to a faster crystallization. ${ }^{18}$ The authors proposed that this is due to the tetrameric nature of $\mathrm{ZrOCl}_{2} .8 \mathrm{H}_{2} \mathrm{O}$ that is rapidly transformed in the presence of terephthalate linkers into the final $\mathrm{Zr}_{6} \mathrm{O}_{4}(\mathrm{OH})_{4}(\mathrm{COO})_{12}$ clusters that are involved in the construction of the UiO-66 framework. Contrarily, the use of $\mathrm{ZrCl}_{4}$ requires hydrolysis and condensation steps, to form first $\mathrm{Zr}(\mathrm{OH})_{4}$ and then the hexamer $\mathrm{Zr}_{6} \mathrm{O}_{4}(\mathrm{OH})_{4}(\mathrm{COO})_{12}$, which slows down the crystallization process and results in larger crystals. Based on this report, we speculated that preparing zirconium precursors with different states of hydration could allow for the systematic modulation of the UiO-66 crystal size. As for the UiO-x-0 samples, the similarity of the XRD patterns of all UiO-2-y samples with the calculated UiO-66 diffractogram confirms that these materials are made of pure UiO-66 phase (Figure 2A, patterns a, d, e and f). However, the peak intensities are strongly decreased and their full widths at half maxima become wider as the $\mathrm{H}_{2} \mathrm{O} / \mathrm{Zr}$ ratio increases, indicating a decrease in the mean crystals size. This trend is also confirmed by TEM analysis (Figure 3). Indeed, while UiO-2-0, which was synthetized according to the standard protocol, is made of aggregated crystals with ill-defined shape and size of approximately $400 \mathrm{~nm}$ (Figure 3a), UiO-2-4, which was prepared with a hydrated $\mathrm{ZrCl}_{4}$ precursor having a $\mathrm{H}_{2} \mathrm{O} / \mathrm{Zr}$ ratio of 4 , is composed of aggregated crystals with a much lower mean size of approximately $100 \mathrm{~nm}$ (Figure 3b). The mean crystal sizes are getting even smaller in UiO-2-6 (40 nm) and UiO-2-9 $(15 \mathrm{~nm})$ (Figure $3 \mathrm{c}$ and $3 \mathrm{~d}$ ). These decreases in crystal sizes when using $\mathrm{Zr}$ precursors with a higher level of hydration are also associated with change in porosity (Figure $2 \mathrm{C}$, isotherms a and $\mathrm{d}$ to $\mathrm{f}$; Table 2). Firstly, a decrease of the microporous volume, likely related to the increase of the crystal growth rate that may induce a slight degradation of the crystal quality. Secondly, an increase of the $\mathrm{N}_{2}$ volume adsorbed at relative pressures higher than 0.7 , due to the generation of inter-crystalline mesopores that are also clearly visible on the TEM images of the UiO-2-6 and UiO-2-9 materials (Figure 3c and 3d). Noticeably, the similar TGA profiles for all UiO-2-y materials (Figure 2B, isotherms a and d to f) confirm that changing the hydration degree of the zirconium precursor while keeping the $\mathrm{BCD} / \mathrm{Zr}$ ratio equal to 2 in the synthesis medium does not affect the number of organic ligands. The number of organic linkers closely corresponds to the ideal number of 6 per $\mathrm{Zr}_{6}$ unit formula, showing an absence of structural defects (no missing ligands, Table 1). In this undefective UiO-66 series of materials, the structure formula after activation at $200^{\circ} \mathrm{C}$ for $20 \mathrm{~h}$ is consequently close to the ideal one $\left(\mathrm{Zr}_{6} \mathrm{O}_{4}(\mathrm{OH})_{4}(\mathrm{bdc})_{6}\right)$.

$\underline{\text { UiO-1-9 sample }}$ - For the sake of comparison, a UiO-66 sample was synthesized with both a deficiency of $\mathrm{BCD}(\mathrm{x}=1)$ and a highly hydrated $\mathrm{Zr}$ precursor $(\mathrm{y}=9)$ in order to obtain a material containing both 
$\mathrm{B}-\mathrm{Zr}_{\mathrm{UC}}$ and $\mathrm{ES}-\mathrm{Zr}_{\mathrm{UC}}$. The diffractogram of this material corresponds to that of pure UiO-66. It is characterized by 0.8 missing linker per $\mathrm{Zr}_{6}$ formula unit and a large external surface area of $467 \mathrm{~cm}^{3} \cdot \mathrm{g}^{-}$ ${ }^{1}$ (Figure 2, curves g and Table 1).
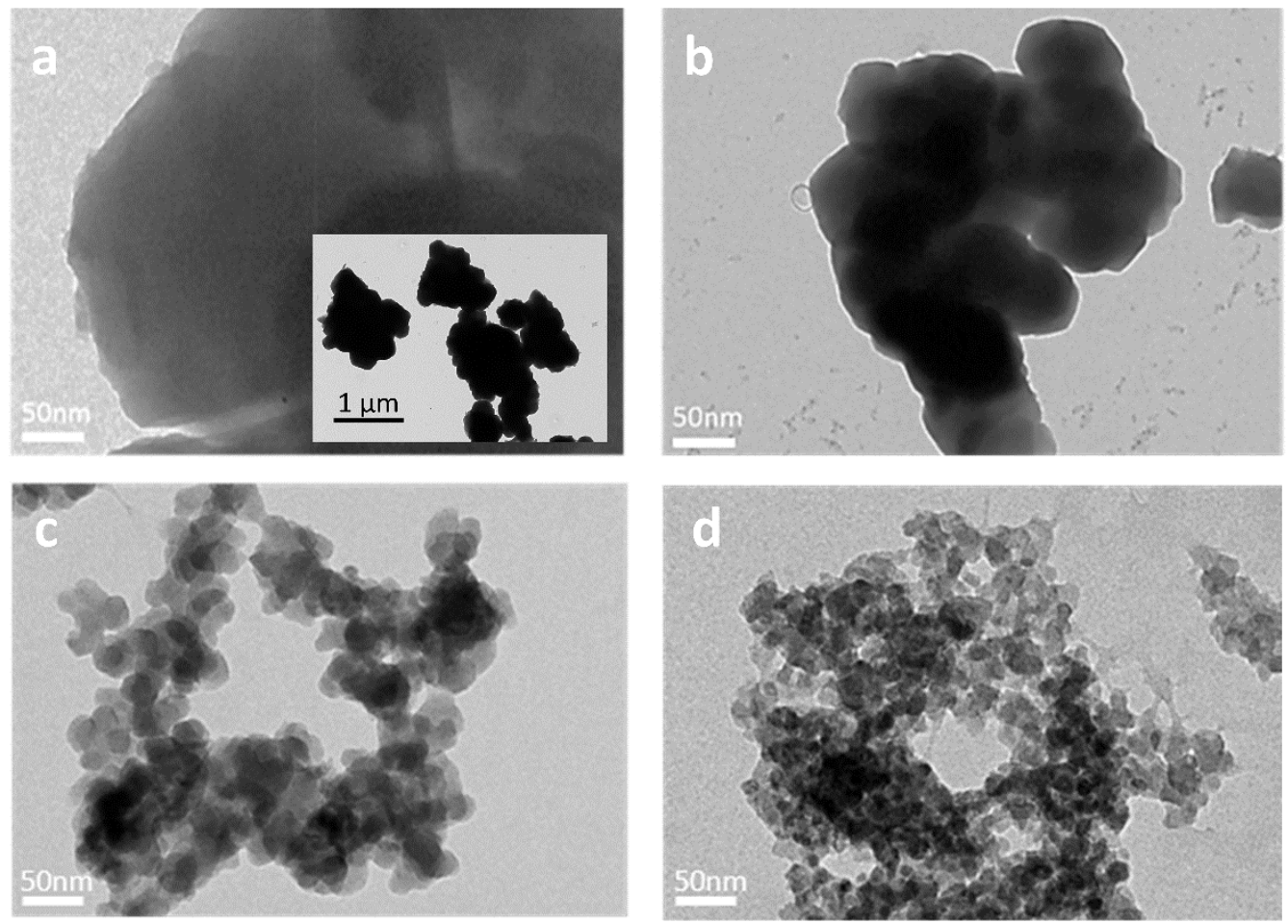

Figure 3 TEM images of (a) UiO-2-0, (b) UiO-2-4, (c) UiO-2-6, and (d) UiO-2-9. 
Table 1. Conditions of synthesis, number of missing linkers, textural properties and crystal sizes for the UiO-x-y series of materials.

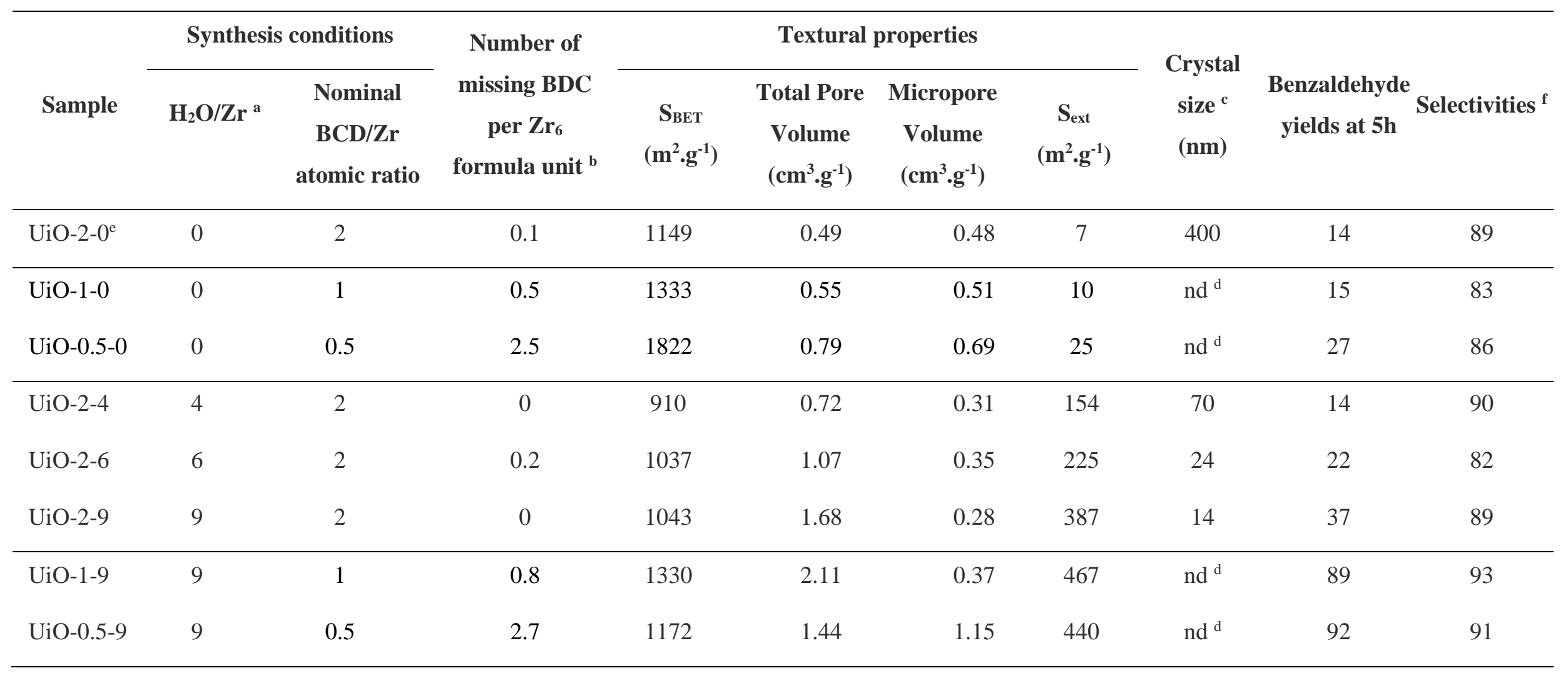

a. $\mathrm{H}_{2} \mathrm{O} / \mathrm{Zr}$ molar ratio in the zirconium precursor used to synthesize the MOF.

b. Determined by thermogravimetric analysis according the calculation method described in reference ${ }^{14}$; the number of $\mathrm{BCD}$ per $\mathrm{Zr}_{6}$ unit formula is ideally 6 .

c. Determined by TEM analysis based on the measure of at least 50 crystals.

d. nd: non determined.

e. Sample prepared following the protocol reported in ref ${ }^{14}$.

f. Selectivities lower than $100 \%$ were obtained. Benzoic acid was likely produced together with benzaldehyde, although it could not be detected by our equipment. 


\section{Spectroscopic characterization of the defective sites.}

In this section, two spectroscopic methods, namely FT-IR of adsorbed $\mathrm{CO}$ molecules and ${ }^{1} \mathrm{H}$ solid-state NMR were applied to evidence the existence at the $\mathrm{Zr}_{\mathrm{UC}}$ centers of either Lewis acid sites or hydroxyl groups depending if the UiO-66 samples were dehydrated or not. As mentioned before, these two species are indeed expected to take part in the catalytic processes involving $\mathrm{Zr}_{\mathrm{UCS}}{ }^{11}$

2.1. Infrared spectroscopy of adsorbed CO (used as a basic probe). This is a well-established technique for probing Brønsted and Lewis acid sites in inorganic catalysts. ${ }^{19}$ It was also recently applied to MOFs. ${ }^{20,21}$ We used it here to identify the formation of Lewis acid sites at the $\mathrm{Zr}_{\mathrm{UC}}$ in the dehydrated defective materials of the UiO-x-0 series i.e. material with negligible density of $\mathrm{ES}-\mathrm{Zr}_{\mathrm{UC}}$ and varying densities of $\mathrm{B}-\mathrm{Zr}_{\mathrm{UC}}$. Before $\mathrm{CO}$ adsorption, the samples were first treated at $200^{\circ} \mathrm{C}$ under flowing argon to desorb the water molecules physisorbed within the pores as well as the terminal $\mu_{1}-\mathrm{OH}$ and $\mathrm{H}_{2} \mathrm{O}$ capping the unsaturated $\mathrm{Zr}_{\mathrm{UC}}$ sites under storage conditions (Figure 1B). Four main absorbance domains are identified on the obtained spectra shown in the $2100-2200 \mathrm{~cm}^{-1}$ characteristic of adsorbed CO (Figure 4A). The broad band at lower wavenumbers, visible in all the samples, is composed of two overlapping bands positioned at $2134 \mathrm{~cm}^{-1}$ and $2128 \mathrm{~cm}^{-1}$, in a range previously reported for solid and liquid $\mathrm{CO}$ and for $\mathrm{CO}$ clathrates. ${ }^{22} \mathrm{We}$ attribute these overlapped signals to $\mathrm{CO}$ physisorbed within the inner pores and intergrain voids of the MOF. In addition, two weaker bands are observed at higher wavelengths. The band at approximately $2150 \mathrm{~cm}^{-1}$ is assigned to $\mathrm{CO}$ adsorbed on the bridging $\mu_{3}-\mathrm{OH}$ moieties still occurring after the $200^{\circ} \mathrm{C}$ treatment at the $\mathrm{Zr}_{6}$ nodes. The band at approximately $2170 \mathrm{~cm}^{-1}$ corresponds to the $\mathrm{CO}$ interacting with the unsaturated $\mathrm{B}-\mathrm{Zr}_{\mathrm{UC}}$ sites through the establishment of dative covalent bonds as proposed by Driscoll et al. ${ }^{20}$ Note that the intensity of the band at $2170 \mathrm{~cm}^{-1}$ systematically increases with the increase in the number of missing linkers in the structure, confirming the creation of a higher number of Lewis acid sites. The trend is however less clear with respect to the evolution of the intensity of the band at $2150 \mathrm{~cm}^{-1}$, indicating a more complex behavior. At this point, it should be recalled that a treatment at $300^{\circ} \mathrm{C}$ of undefective UiO-66 provoke the reversible loss of 2 water molecules from each hydrated $\left[\mathrm{Zr}_{6} \mathrm{O}_{4}(\mathrm{OH})_{4}\right]^{12+}$ inorganic brick present at the nods to give fully dehydroxylated $\left[\mathrm{Zr}_{6} \mathrm{O}_{6}\right]^{12+}$ bricks; ${ }^{23}$ during this process, the $4 \mu_{3}-\mathrm{OH}$ and $4 \mu_{3}-\mathrm{O}$ moieties of the hydrated brick (blue and red circles, Figure S1) are replaced by $6 \mu_{3}-\mathrm{O}$ moieties (red circles, Figure S1) and this is accompanied by the formation of 6 unsaturated zirconium sites. Having this in mind, the temperature of $200^{\circ} \mathrm{C}$ used first to dehydrate the samples (Figure $4 \mathrm{~A}$ ) was not high enough to eliminate the $\mu_{3}-\mathrm{OH}$ moieties in the case of the undefective UiO-2-0 sample (more stable), for which the $2150 \mathrm{~cm}^{-1}$ signal is the highest. As expected, this band disappeared after treatment of UiO-66 at $300^{\circ} \mathrm{C}$ (Figure $4 \mathrm{~B}$, spectrum a) and the process was reversible after partial rehydration and new treatment at $200^{\circ} \mathrm{C}$ (Figure $4 \mathrm{C}$, spectrum a). The departure of most of the $\mathrm{OH}$ groups after treatment at $300{ }^{\circ} \mathrm{C}$ was also confirmed by the nearly total disappearance of the characteristic $\mathrm{OH}$ signals on the $\mathrm{OH}$ vibrational range of the FT-IR spectra (Figure S2) and on ${ }^{1} \mathrm{H}$ solid-state NMR spectra corresponding to the dehydrated samples in Figure 5A and B (see below). Based on these observations, we can assume that the very weak $2150 \mathrm{~cm}^{-}$ 
${ }^{1}$ signal for sample UiO-1-0 (whatever the temperature of treatment) and the slightly more intense one for UiO-0.5-0 (at $200^{\circ} \mathrm{C}$ ) are the result of a combined variation in the stability and content of the $\mu_{3}-\mathrm{OH}$ groups due to the occurrence of missing linkers (structural defects) in those samples. These groups could indeed be less stable than in undefective UiO-66 and hence more sensitive to dehydroxylation at $200{ }^{\circ} \mathrm{C}$, potentially explaining the very weak $2150 \mathrm{~cm}^{-1}$ signal for UiO-1-0 even at this temperature. The amount of defects and their impact on their neighborhood would be however too high in UiO-0.5-0 to allow the full removing of these $\mu_{3}-\mathrm{OH}$ at $200{ }^{\circ} \mathrm{C}$, and some of them even seem to remain at $300^{\circ} \mathrm{C}$ (weak $2150 \mathrm{~cm}^{-1}$ band on spectrum c, Figure 4B). Nevertheless, at this higher temperature, the increase in intensity of the band at $2170 \mathrm{~cm}^{-1}$ with the increase in the amount of missing linkers is clear, confirming the creation of Lewis acid sites consecutive to missing ligands within the defective materials.
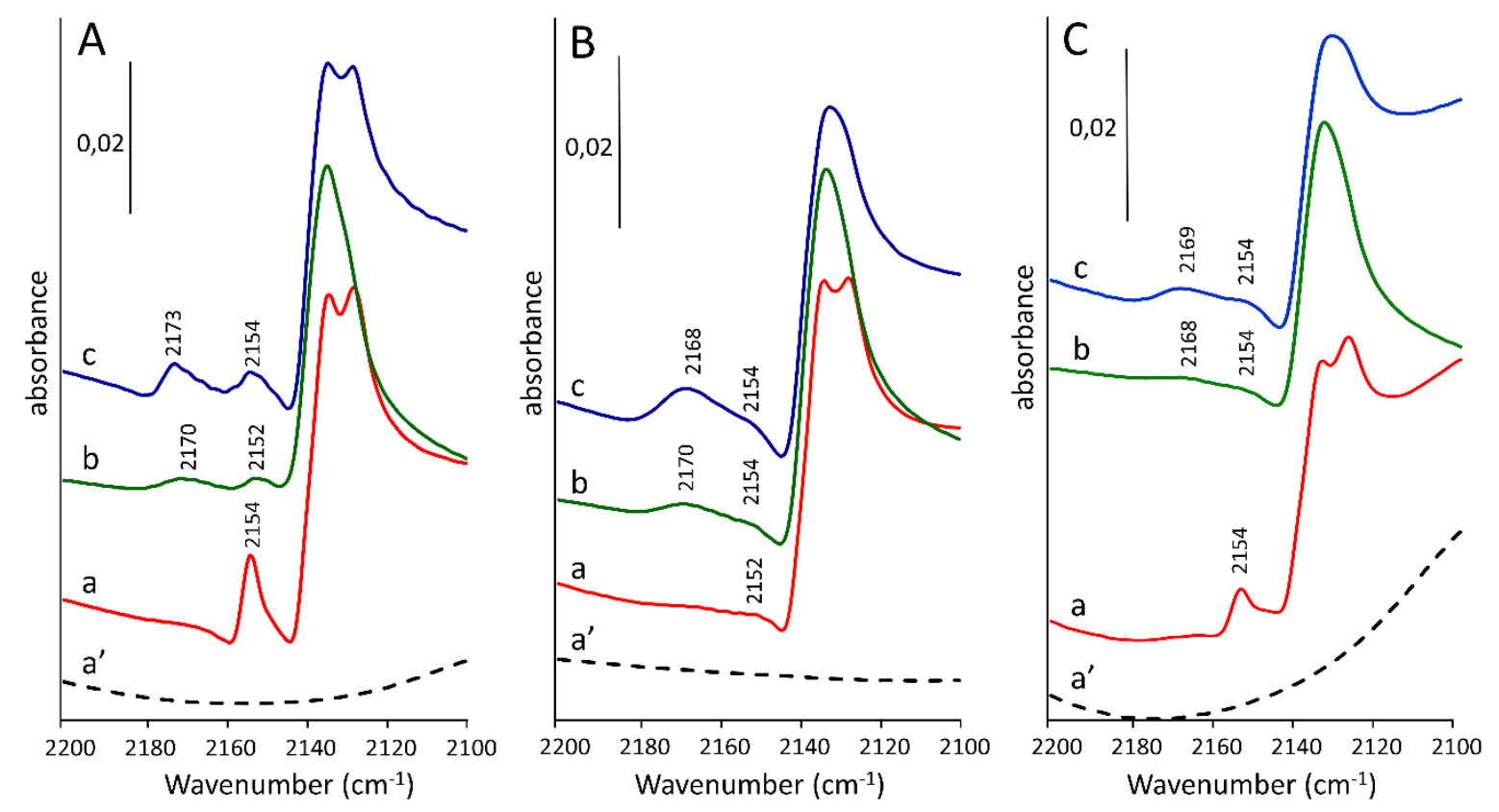

Figure 4. FTIR spectra of $\mathrm{CO}$ (133 Pa) adsorbed at $-173{ }^{\circ} \mathrm{C}$ on dehydrated (a) UiO-2-0, (b) UiO-1-0 and (c) UiO-0.5-0 after treatment of the samples at (A) $200^{\circ} \mathrm{C},(\mathbf{B}) 300^{\circ} \mathrm{C}$ and (C) $300^{\circ} \mathrm{C}$ followed by a partial rehydration and new treatment at $200^{\circ} \mathrm{C}$; (a') spectrum of UiO-2-0 treated in the same conditions but before adsorption of $\mathrm{CO}$. The spectra are normalized with respect to the adsorption band at $1507 \mathrm{~cm}^{-}$ ${ }^{1}$ corresponding to the aromatic ring of the linkers.

2.2. ${ }^{1}$ H solid-state MAS NMR spectroscopy. As already illustrated in Figure $1 \mathrm{~B}$, the $\mathrm{Zr}_{\mathrm{UC}}$ pairs originating from a missing carboxylate group in defective UiO-66 hydrated under ambient conditions are known to be capped by a water molecule and a charge compensating terminal hydroxy moieties. The proton of this terminal $\mu_{1}-\mathrm{OH}$ group is expected to display a characteristic NMR signature that could be exploited to indirectly probe the occurrence of the $\mathrm{Zr}_{\mathrm{UC}}$ sites by solid-state ${ }^{1} \mathrm{H}$ MAS NMR spectroscopy. Determination of this signal was first achieved by monitoring the ${ }^{1} \mathrm{H}$ MAS NMR signals between -2 and 11 ppm during progressive rehydration (for $5 \mathrm{~h}$, at c.a. $30 \%$ humidity) of UiO-2-0 (large crystals without 
structural defects, Figure 5A) and UiO-1-0 (large crystals with structural defects, Figure 5B). The samples were previously dehydroxylated at $300{ }^{\circ} \mathrm{C}$ under $\operatorname{Ar}$ (as for above FTIR experiments), resulting in fully dehydroxylated brick $\left[\mathrm{Zr}_{6} \mathrm{O}_{6}\right]^{12+}$ containing $6 \mu_{3}-\mathrm{O}$ moieties and 6 unsaturated zirconium sites, (Figure S1).

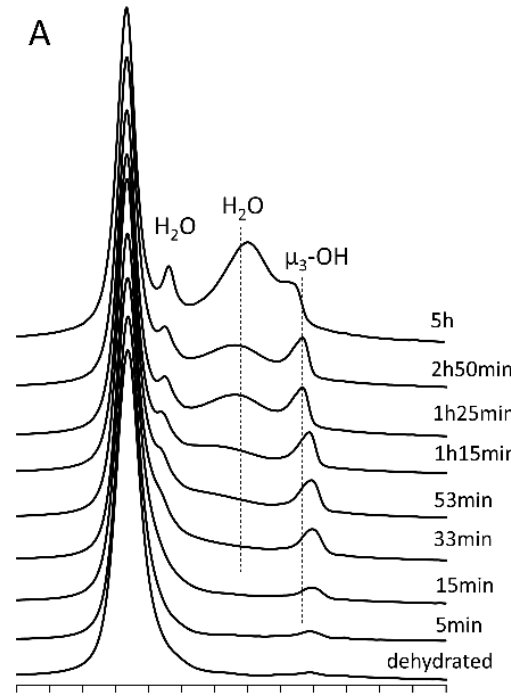

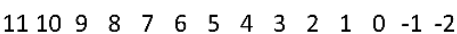
$\delta(\mathrm{ppm})$

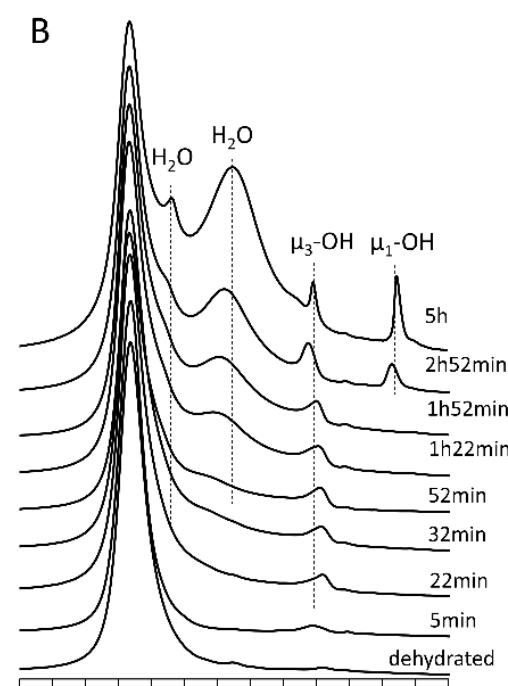

$\begin{array}{llllllllllllll}11 & 10 & 9 & 8 & 7 & 6 & 5 & 4 & 3 & 2 & 1 & 0 & -1 & -2\end{array}$ $\delta(\mathrm{ppm})$

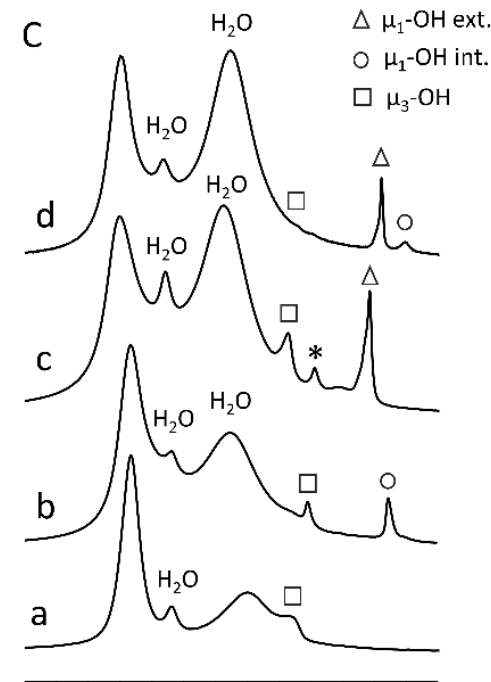

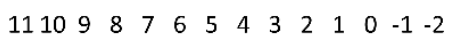
$\delta(\mathrm{ppm})$

Figure 5. ${ }^{1} \mathrm{H}$ solid-state MAS NMR spectra of (A) UiO-2-0 (large crystals without defects) and (B) UiO-1-0 (large crystals with defects) dehydrated (5 min at $\mathrm{T}=300{ }^{\circ} \mathrm{C}$ under argon stream) and after different times of exposure ( 0 to $5 \mathrm{~h}$ ) to ambient atmosphere (relative humidity of approximately $30 \%$ ); (C) ${ }^{1} \mathrm{H}$ solid-state MAS NMR spectra of hydrated (a) UiO-2-0, (b) UiO-1-0, (c) UiO-2-9 (the smallest nanocrystals without defects) and (d) UiO-1-9 (the smallest nanocrystals with defects). The terms $\mu_{1^{-}}$ $O H_{\text {ext. }}$ and $\mu_{1}-\mathrm{OH}_{\text {int. }}$ stand for the terminal $\mu_{1}-\mathrm{OH}$ coordinated at the $\mathrm{Zr}_{\mathrm{UC}}$ centers (Scheme 1) occurring onto the external surface $\left(\mathrm{ES}-\mathrm{Zr}_{\mathrm{UC}}\right)$ and within the framework of the crystals $\left(\mathrm{B}-\mathrm{Zr}_{\mathrm{UC}}\right)$, respectively. The star indicates an unattributed peak.

Before exposure to the moisture of the ambient atmosphere, the freshly dehydrated UiO-2-0 and UiO1-0 samples display similar spectra composed of (i) a main peak at $7.9 \mathrm{ppm}$ attributed to the 4 hydrogen atoms at the aromatic ring of the BDC linkers and (ii) a very weak peak at approximately 2 ppm that we tentatively attribute to the protons of a small amount of bridging $\mu_{3}-\mathrm{OH}$ remaining at the zirconium nodes after the thermal treatment or formed by probable (uneasy to avoid) water adsorption during transfer of the rotor to the magnet. Exposing the two samples to ambient moisture quickly leads to a regular growth of the $2 \mathrm{ppm}$ peak (from about 5 to $30 \mathrm{~min}$ ), suggesting the progressive regeneration of the bridging $\mu_{3}-\mathrm{OH}$ moieties eliminated during the thermal treatment. ${ }^{24}$ Interestingly, this is in line with the regeneration of the $\mu_{3}-\mathrm{OH}$ moieties already observed above by FTIR spectroscopy (band at 2150 $\mathrm{cm}^{-1}$ of adsorbed $\mathrm{CO}$, Figure 4C), which supports our attribution of the $2 \mathrm{ppm}$ NMR signal to the proton of bridging $\mu_{3}-\mathrm{OH}$ moieties, never experimentally proved so far to our knowledge. Water physisorption 
within the pores is also observed from the progressive appearance of a broad peak between 4 and 5 ppm and the concomitant formation of a shifted signal at $6.5 \mathrm{ppm}$ assignable to protons of water molecules weakly interacting with species at their vicinity. ${ }^{25}$ These trends are similar for both UiO-2-0 and UiO$1-0$ during the first $1.5 \mathrm{~h}$ of exposure to ambient humidity, but the spectra interestingly differ afterwards. Firstly, the peaks related to physisorbed water are accentuated for UiO-1-0 compared to UiO-2-0, revealing, as expected, a higher hydration level in the more defective material. Secondly, a new peak at $-0.6 \mathrm{ppm}$ is observed for UiO-1-0, at longer rehydration time (above $2 \mathrm{~h}$ ), but not for UiO-2-0, assignable to the formation of terminal $\mu_{1}-\mathrm{OH}$ by adsorption and dissociation of water molecules on $\mathrm{Zr}_{\mathrm{UC}}$ sites. ${ }^{26}$ Indeed, the peaks at chemical shifts below $1 \mathrm{ppm}$ were reported by Lawrence et al. who tentatively assigned them to terminal $\mu_{1}-\mathrm{OH}$ and water moieties at defect sites in UiO-67. ${ }^{27}$ For the sake of further comparison, the spectra of hydrated UiO-2-0 and UiO-1-0 were also recorded (after 5h, Figure 5Ca and b), confirming that the additional peak observed at -0.6 ppm for UiO-1-0 is the only difference between them. Above assignment is further supported by HetCore experiments which proved that the proton detected at this low chemical shift value is not linked to any carbon atom and therefore belongs to either a water molecule or a hydroxy group (Figure S3). A correlation therefore exists between these ${ }^{1} \mathrm{H}$ MAS NMR results and the above FTIR data involving $\mathrm{CO}$ adsorption on the same materials, both attesting of the occurrence of structural B- $\mathrm{Zr}_{\mathrm{UC}}$ defect sites in UiO-1-0. These sites are detectable by either the -0.6 ppm signal ( ${ }^{1} \mathrm{H}$ MAS NMR, rehydrated sample) or the $2170 \mathrm{~cm}^{-1}$ (FTIR in presence of adsorbed CO) signatures. Hence, both techniques can be complementary employed to qualitatively monitor the presence of Lewis acid sites generated by missing linkers in UiO-66 type MOFs, but their feasibility requires a distinct hydration state of the material.

${ }^{1} \mathrm{H}$ MAS NMR spectroscopy was then used to evidence the formation of ES-Zr $\mathrm{r}_{\mathrm{UC}}$ on the surface of the hydrated smallest crystals. To do so, the ${ }^{1} \mathrm{H}$ MAS NMR spectrum of hydrated UiO-2-9 (small crystals without B-Zr $\mathrm{r}_{\mathrm{UC}}$ defects, Figure 5Cc) was compared to that of hydrated UiO-2-0 (big crystals without B$\mathrm{Zr}_{\mathrm{UC}}$ defects, Figure 5Ca), showing the appearance of a new thin peak at c.a. $0.2 \mathrm{ppm}$ for the small crystals. This chemical shift value is slightly higher than $-0.6 \mathrm{ppm}$ found above for defective UiO-1-0 (Figure 5Cb), but it remains below $1 \mathrm{ppm}$. By analogy, and in view of the very small sizes of the UiO2-9 crystals (and therefore of the very high external surface of this sample), we attribute this $0.2 \mathrm{ppm}$ peak to the hydrogen atoms of terminal $\mu_{1}-\mathrm{OH}$ located at unsaturated external ES- $\mathrm{Zr}_{\mathrm{UC}}$ sites (Figure 1B). Noteworthy, the higher chemical shift for terminal $\mu_{1}-\mathrm{OH}$ at $\mathrm{ES}-\mathrm{Zr}_{\mathrm{UC}}$ sites $(\delta=0.2 \mathrm{ppm})$ compared to that at $\mathrm{B}-\mathrm{Zr}_{\mathrm{UC}}$ sites $(\delta=-0.6 \mathrm{ppm})$ might be due to the different local environments and sites configurations that vary depending whether the $\mathrm{Zr}_{\mathrm{UC}}$ is located within the confined space of the pores or rather on exposed open external surfaces. Such different local environment of terminal $\mu_{1}-\mathrm{OH}$ positioned into the pores or at external surfaces may also explain the different shapes observed for the peaks at $\delta=$ $-0.6 \mathrm{ppm}$ (for $\mathrm{UiO}-1-0$ ) and $0.2 \mathrm{ppm}$ (for $\mathrm{UiO}-2-9$ ): the former, associated to $\mu_{1-} \mathrm{OH}$ groups located within a rigid and uniform pore environment (labeled $\mu_{1}-\mathrm{OH}_{\text {int }}$, circle in Figure $5 \mathrm{Cb}$ ), is symmetrical, while the latter, due to $\mu_{1}-\mathrm{OH}$ groups on the external surface (labeled $\mu_{1}-\mathrm{OH}_{\text {ext }}$, square in Figure $5 \mathrm{Cc}$ ) is 
sharp but slightly asymmetrical, likely due to the mobility of pending BDC ligands located in the direct surrounding. This would also explain why the peak at $0.2 \mathrm{ppm}$ seems to be composed of more than one peak.

Interestingly, ${ }^{1} \mathrm{H}$ solid state MAS NMR analysis also confirms the coexistence of the two types of partially uncoordinated zirconium site, $\mathrm{B}-\mathrm{Zr}_{\mathrm{UC}}$ and $\mathrm{ES}-\mathrm{Zr}_{\mathrm{UC}}$, in UiO-1-9 (Figure 3Cd). Thus, the spectrum of hydrated UiO-1-9 displays two distinct peaks at negative chemical displacement values $(\delta$ $=-0.3 \mathrm{ppm}$ and $-0.9 \mathrm{ppm})$, attributable to both types of terminal $\mu_{1}-\mathrm{OH}$. Firstly, the sharp peak at $\delta=-$ $0.3 \mathrm{ppm}$, likely due to $\mu_{1}-\mathrm{OH}_{\text {ext }}$ groups on $\mathrm{ES}-\mathrm{Zr}_{\mathrm{UC}}$ surface sites, is asymmetrical, as for the $0.2 \mathrm{ppm}$ peak of terminal $\mu_{1}-\mathrm{OH}_{\text {ext }}$ at ES-Zr $r_{\mathrm{UC}}$ sites in hydrated UiO-2-9 (Figure 3Cc); the observed slight $\delta$ value difference between the two samples could come from a different hydration degree when the NMR measurements were performed. Secondly, the peak at $\delta=-0.9 \mathrm{ppm}$ appears at a low negative $\delta$ value, close to that observed for the $\mu_{1}-\mathrm{OH}_{\text {int }}$ groups in defective UiO-1-0 ( $\left.\delta=-0.6 \mathrm{ppm}\right)$ (Figure 3B), being therefore assignable to protons of internal (bulk) $\mu_{1}-\mathrm{OH}_{\text {int }}$ groups at $\mathrm{B}-\mathrm{Zr}_{\mathrm{UC}}$ zirconium centers created by missing linkers within the UiO-1-9 framework. The weak intensity of this peak can be easily explained by the low volume to surface ratio in UiO-1-9 (small crystals) compared to UiO-1-0 one (UiO$\mathrm{x}-0$ series, big crystals).

\section{Catalytic activity.}

All catalytic tests were achieved by performing the benzyl alcohol (BA) oxidation in pure acetonitrile at $\mathrm{T}=40^{\circ} \mathrm{C}$ under ambient atmosphere using tert-butyl hydroperoxide (TBHP) as oxidizing agent and a BA/TBHP molar ratio of 0.5 . The two series of catalysts, UiO-x-0 and UiO-2-y were employed with the aim to monitor the implication of the $\mathrm{Zr}_{\mathrm{UC}}$ sites at the two different locations in $\mathrm{BA}$ oxidation reaction.

The first test, carried out in the presence of defect-free UiO-2-0 resulted in benzaldehyde yield of $18 \%$ after $22 \mathrm{~h}$ of reaction (see panel A, Figure 6). Such existing (although modest) catalytic activity at first glance was surprising for a material free of any defect in its structure. However, a reference test achieved in the absence of any catalyst resulted in a comparable benzaldehyde yield (18\%) after $22 \mathrm{~h}$, revealing some production of benzaldehyde intrinsic to the catalytic test set up. Since TBHP is not expected to react with BA spontaneously (without a catalyst) at the relatively low temperature applied for the test $\left(\mathrm{T}=40{ }^{\circ} \mathrm{C}\right)$, the occurrence of reactive radical species within the TBHP batch employed for the experiment was suspected and confirmed by electron spin resonance (ESR) analysis carried out at liquid nitrogen temperature. Indeed, a TBHP batch mixed with an acetonitrile solution of DMPO as spin trap gave a signal with $\mathrm{g}=2.0047, \mathrm{a}_{\mathrm{N}}=13.63 \mathrm{G}$ and $\mathrm{a}_{\mathrm{H}}=10.92 \mathrm{G}$, typical of the hydroperoxyl HOO radical adduct (DMPO-OOH) (Figure S4a) as also shown by its superimposition with the DMPO-OOH computer simulation ESR spectrum presented in Figure S5. The signal was decreased when BA was added together with DMPO in the TBHP acetonitrile solution (Figure S4b), showing that BA reacts with HOO: Moreover, this signal was no longer detected when DMPO was added in the reference reaction 
medium after $1 \mathrm{~h}$ of reaction (Figure $\mathrm{S} 4 \mathrm{c}$ ) while benzaldehyde was produced, strongly suggesting that this production resulted from the reaction between BA and HOO' radicals. However, as stressed in the following sections, the role of these radical species in the oxidation process is negligible. Since other fresh TBHP batches gave the same results and the presence of these radicals species seems to be unavoidable, it was decided to continue with the same TBHP batch in the following and to consider all yields below $18 \%$ as artefacts coming from this radical-induced side reaction when comparing the activity of the different catalysts.

3.1. Role of the $B-Z_{U C}$ sites. Despite depicting a default number of 0.5 missing linker per $\mathrm{Zr}_{6}$ formula unit, UiO-1-0 did not lead to better performance than UiO-2-0. In contrast, using UiO-0.5-0 whose number of missing linkers per $\mathrm{Zr}_{6}$ formula unit is 2.5 , resulted in a significantly higher benzaldehyde yield after $22 \mathrm{~h}$ of reaction (yield $=55 \%$ ) with a selectivity of $94 \%$. This increase shows that bulk Lewis acid sites generated by missing linkers (Figure 2a) in the UiO-66 structure can provide catalytic activity for the oxidation of BA at low temperature but they have to be numerous enough (and accessible enough) to make the BA oxidation possible. In addition to generate active $\mathrm{B}-\mathrm{Zr}_{\mathrm{UC}}$ Lewis acid sites, a higher number of missing linkers might also facilitate the access to the active sites and provide more space for the reaction to proceed by increasing the micropores volume as discussed in section 1 (Figure 2 and Table 1). These results are in accordance with the conclusions of Vermoortele et al. who showed that a high number of missing linkers in UiO-66 is required to successfully catalyze the "ene"-type cyclization of the bulky citronellal to isupulegol. ${ }^{28}$

3.2. Role of the $\boldsymbol{E S}-\mathrm{Zr}_{U C}$ sites. Figure $6 \mathrm{~B}$ shows the catalytic results obtained with the UiO-2-y series of catalysts having different crystal sizes and $\mathrm{B}-\mathrm{Zr}_{\mathrm{UC}}$ densities close to zero. It shows a significant increase of the reaction rate with the decrease of the crystal size. Thus, after $31 \mathrm{~h}$, the benzaldehyde yield increases from $20 \%$ to $80 \%$ when the crystal size decreases from $400 \mathrm{~nm}$ to $14 \mathrm{~nm}$. This linearity in the relationship between the external surface area of the crystals and the benzaldehyde yield (plotted in Figure 7) strongly suggests the important role of the ES-Zr $\mathrm{UC}_{\mathrm{UC}}$ sites in the oxidation process. In view of these higher performances of the $\mathrm{ES}-\mathrm{Zr}_{\mathrm{UC}}$ sites compared to the $\mathrm{B}-\mathrm{Zr}_{\mathrm{UC}}$ ones, it can be assumed that the opened environment surrounding the $\mathrm{ES}^{-\mathrm{Zr}_{\mathrm{UC}}}$ sites on the crystal surface is more favorable for the alcohol oxidation to proceed.

3.3. Combining $\boldsymbol{B}-Z \boldsymbol{r}_{U C}$ and $\boldsymbol{E S}-\mathbf{Z} \boldsymbol{r}_{U C}$. The concomitant effect of the two types of defects upon catalytic activity of UiO-66 was also studied, using the defect- and size-engineered UiO-1-9 material having at the same time 0.8 missing linker per $\mathrm{Zr}_{6}$ formula unit and high external surface area and pores volume (Table 1).

The coexistence of $\mathrm{B}-\mathrm{Zr}_{\mathrm{UC}}$ and $\mathrm{ES}-\mathrm{Zr}_{\mathrm{UC}}$ sites led to a drastic increase of the catalytic performances, with a benzaldehyde yield higher than $80 \%$ after only $1 \mathrm{~h}$ of reaction (Figure 6B). UiO-0.5-9, a sample also possessing a high external surface area (Figure S6 and Table 1) and containing an even higher number of missing linkers per $\mathrm{Zr}_{6}$ formula (2.7 missing linker per unit formula) (Figure $2 \mathrm{~B}$ and Table 1) than UiO-1-9 was also prepared and its superior catalytic activity confirmed the importance of combining 
bulk and external surface $\mathrm{Zr}_{\mathrm{UC}}$ sites within UiO-66 crystals. The combination of both types of sites in the material along with enhanced pore volume owing to the missing linkers allow to maximize the total amount of accessible $\mathrm{Zr}_{\mathrm{UC}}$ sites, facilitate the mass transport and provide some additional room around the $\mathrm{B}-\mathrm{Zr}_{\mathrm{UC}}$ sites, thus significantly enhancing the activity of UiO-1-9 for BA oxidation reaction.

Compared to other MOF-based catalysts employed in the oxidation of benzyl alcohol with TBHP and $\mathrm{O}_{2}$ as oxidant in the literature, the samples UiO-1-9 and UiO-0.5-9 exhibit similar or better performances at similar or lower reaction times and temperatures, with MOF amounts similar than those commonly employed and without the addition of co-catalysts (see the comparison Tables S1 and S2 and corresponding references in supplementary information). Noteworthy, these performances were obtained without the resort to any post-synthetic framework modification steps or active species incorporations.
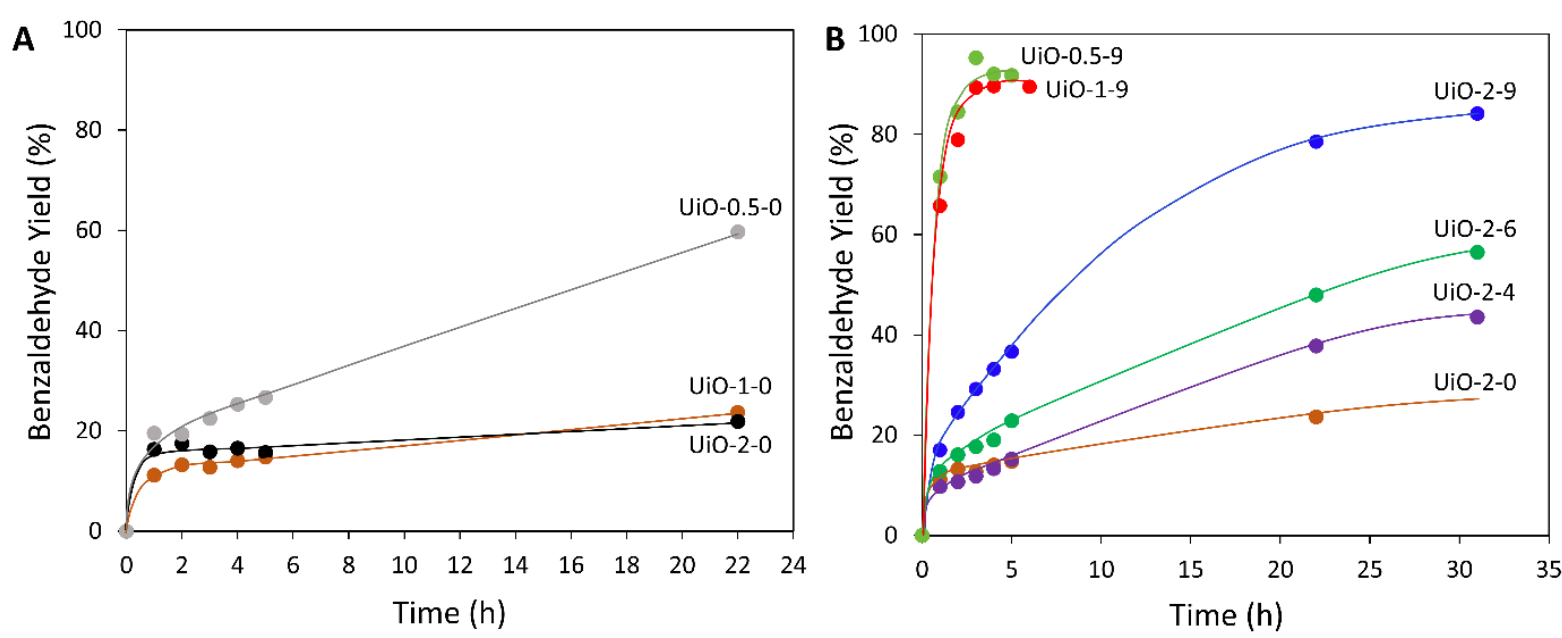

Figure 6. Oxidation of benzyl alcohol by TBHP catalyzed by (A) large crystals of UiO-66 with varying number of structure defects (UiO-x-0 series) and (B) crystals of UiO-66 of varying size without any structural defect (UiO-2-y series). Results obtained with small crystals containing structure defects (UiO-1-9 and UiO-0.5-9) are also shown in red. Test conditions: molar BA/TBHP ratio $=0.5, \mathrm{~V}_{\mathrm{CH} 3 \mathrm{CN}}=$ $0.5 \mathrm{~mL}, \mathrm{~T}=40{ }^{\circ} \mathrm{C}$. 


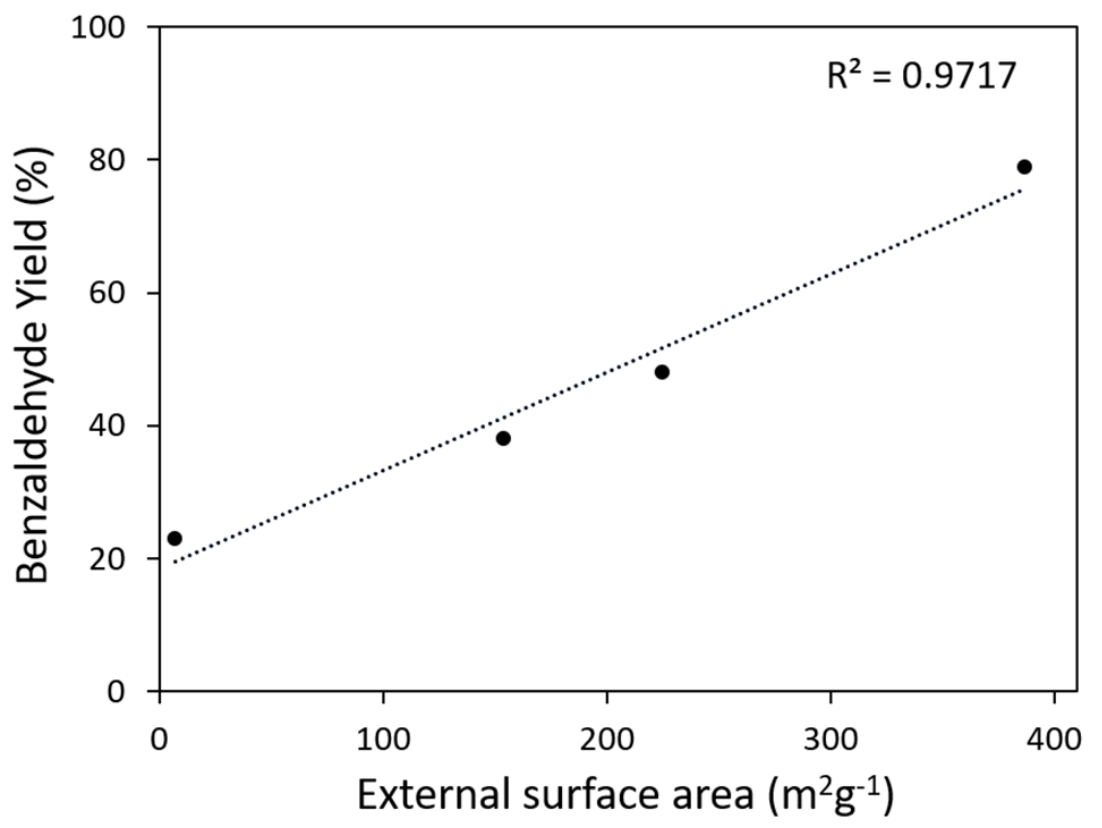

Figure 7. Linear correlation between the yields of benzaldehyde measured after $22 \mathrm{~h}$ of reaction and the external surface area of the series of undefective UiO-66 with various crystal sizes: UiO-2-0, UiO-2-4, UiO-2-6 and UiO-2-9. Test conditions: molar BA/TBHP ratio $=0.5, \mathrm{~V}_{\mathrm{CH} 3 \mathrm{CN}}=0.5 \mathrm{~mL}, \mathrm{~T}=40^{\circ} \mathrm{C}$.

3.4. Heterogeneity and recyclability of the catalytic system. To ascertain the heterogeneous character of the catalysts, an additional experiment was performed by removing the active UiO-2-6 catalyst from its reaction medium by filtration after $1 \mathrm{~h}$ and monitoring the activity of the filtrate (Figure S7). The absence of reaction indicated the absence of active sites leaching in the medium and pointed to the fully heterogeneous character of the catalytic process (data not shown). Noteworthy, this result also points out the negligible implication in the reaction of free hydroperoxyl HOO- radicals detected within the commercial batch of TBHP in the absence of MOF. The inconsequential role of these radical species in the alcohol oxidation catalyzed by UiO-66 catalysts was further confirmed by achieving benzyl alcohol oxidation with TBHP in the presence of added dibutylated hydroxytoluene, a common radical trap, ${ }^{29}$ which did not result in any decrease of the benzaldehyde yield after $24 \mathrm{~h}$ of reaction (Figure S8). In line with this result, ESR analysis of the reaction medium in the presence of DMPO (reaction time $=30 \mathrm{~min}$ ) did not evidence the formation of any of the radical species that are expected in alcohol oxidation with HOO ( see comment S2 in SI). Furthermore, the benzaldehyde selectivity close to $100 \%$ found with all the catalysts tested in this study also suggests a controlled oxidation process, unlikely to be observed in the presence of free radical species that are expected to result in over oxidization of alcohol into carboxylic acid.

Finally, the recyclability of the catalysts was demonstrated by reusing UiO-0.5-9 five times subsequently. The benzaldehyde yield was plotted as a function of the time of reaction during the first $5 \mathrm{~h}$ (Figure 8). Between two consecutive tests, the catalyst was recovered by centrifugation and 
thoroughly washed with acetonitrile. Similar high benzaldehyde yields were obtained for the first three cycles. A decrease was then observed for the fourth and fifth cycles. This decrease is explained by the partial degradation of the UiO-0.5-9 structure after three cycles. UiO-0.5-9 is indeed composed of the smallest and most defected crystals, and therefore may possesses the most fragile structure.

Noteworthy, the effect of the amount of catalyst (UiO-1-9) over the benzaldehyde yield was also studied (Figure S9). The $30 \mathrm{mg} / \mathrm{mmol}$ of catalyst used within all catalytic tests in this study could be reduced by twice without altering the catalysis performance. A benzaldehyde yield of $65 \%$ was still obtained by reducing the amount of catalyst to $10 \mathrm{mg}$.

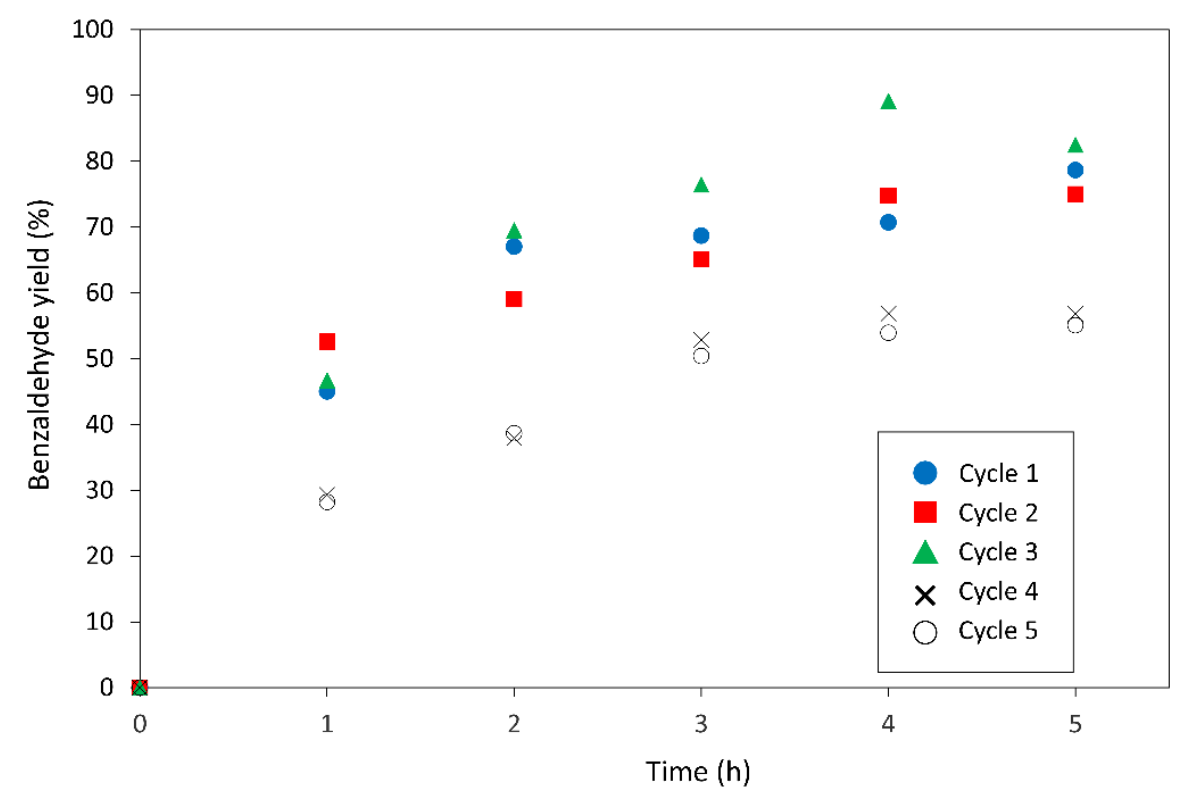

Figure 8. Effect of catalyst recycling on the yield of benzaldehyde obtained from the oxidation of benzyl alcohol with UiO-0.5-9 as catalyst.

\section{Alcohol oxidation mechanism.}

The dependence of the catalyst performances on the density of $\mathrm{Zr}_{\mathrm{UC}}$ sites (Figures 6 and 7 ) indicates the involvement of these sites in the process of benzyl alcohol oxidation by TBHP. Based on this consideration, it is proposed that the alcohol oxidation using TBHP as oxidizing agent and UiO-66 as catalyst occurs through a catalytic oxidative dehydrogenation process taking place according to a concerted hydride transfer pathway. This pathway is similar to those proposed by Krohn et al. employing zirconium isopropoxide as catalyst ${ }^{4}$ or by De Vos et al. in their report on the Oppenauer reaction catalyzed by the UiO-66. ${ }^{11}$ In the possible mechanism shown in Figure 9, TBHP first substitutes one molecule of water adsorbed on one of the two adjacent zirconium centers at the defect sites. Extraction of the acidic proton of TBHP by the terminal $\mu_{1}-\mathrm{OH}$ hydroxide leads to the removal of a water molecule which is replaced by BA. The simultaneous coordination of TBHP and BA on the zirconium centers and their proximity activate both the $\mathrm{O}-\mathrm{O}$ bond of TBHP and the $\mathrm{C}-\mathrm{H}$ bond of $\mathrm{BA}$ and thereby facilitate the 
hydrogen transfer, which supposedly occurs through the setting of a six-membered transition state. The reaction results in the formation of one molecule of tert-butyl alcohol and one molecule of benzaldehyde.

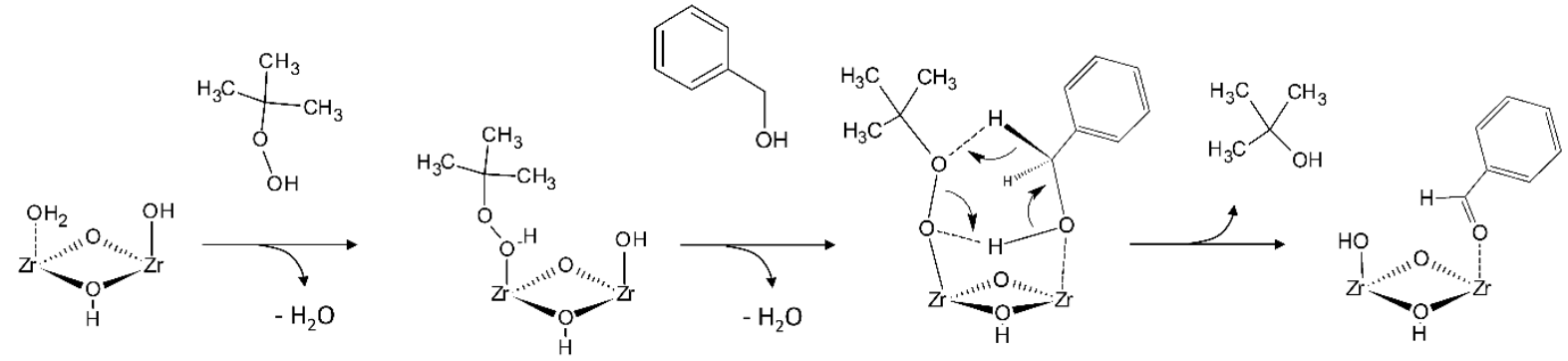

Figure 9. Possible reaction mechanism implying a hydride transfer from BA to TBHP at the free zirconium pairs.

A first indication supporting a mechanism implying the simultaneous coordination of the relatively bulky BA and TBHP on the two $\mathrm{Zr}_{\mathrm{UC}}$ of a same $\mathrm{Zr}-\mathrm{O}(\mathrm{H})-\mathrm{Zr}$ pair is the requirement of enough free space around the $\mathrm{Zr}_{\mathrm{UC}}$ pairs for the reaction to proceed. The best catalytic results were indeed obtained with UiO-66 crystals displaying high external surface areas and/or large number of missing linkers giving higher pores volumes (Figure 6). An additional clue supporting the proposed mechanism is the requirement of at least one equivalent of TBHP with respect to the alcohol to reach the maximal benzaldehyde yield of $90 \%$ after $5 \mathrm{~h}$ of reaction with UiO-1-9. All catalysis tests in this study were performed with an excess of TBHP ( 2 equivalents with respect to the alcohol). However, Figure S10 shows that one equivalent would actually be enough to reach the same yield value. Besides, 0.5 equivalent of TBHP, namely a default of TBHP with respect to the alcohol, results in a clear decrease of the benzaldehyde yield, which fall to $45 \%$. A stoichiometric amount of TBHP is therefore required for the reaction to proceed optimally. Finally, the results of the tests performed with other types of alcohols than benzyl alcohol are also comforting the mechanism in Figure 9. Indeed, furfuryl alcohol, which is less bulky than benzyl alcohol but bears a coordinating furan oxygen atom in $\alpha$ position of the hydroxyl group, did not react at all, suggesting that its ability to bridge the two adjacent $\mathrm{Zr}_{\mathrm{UC}}$ sites prevents the simultaneous adsorption of TBHP (as illustrated in Figure S11). Interestingly, menthol also failed to react and we speculate that this is due to the bulky isopropyl group in $\alpha$ position of the alcohol moieties and the 3-dimensional chemical structure of the cyclohexyl ring that also obstructs the concomitant adsorption of TBHP to the adjacent $\mathrm{Zr}_{\mathrm{UC}}$ of the $\mathrm{Zr}-\mathrm{O}(\mathrm{H})-\mathrm{Zr}$ pairs (Figure S11). Finally, 2hexanol, a substrate known to be challenging and less reactive than furfuryl alcohol and menthol, but does not bear any additional coordinative or bulky substituents capable of sterically hinder the access to the neighbor $\mathrm{Zr}_{\mathrm{UC}}$ was efficiently oxidized (yield of $62 \%$ after $4 \mathrm{~h}$ of reaction). These results therefore also support a reaction mechanism in which the concomitant accessibility of the alcohol and TBHP to the two adjacent $\mathrm{Zr}_{\mathrm{UC}}$ is a prerequisite for the reaction to occur. 
Beside the 2-hexanol, 2-methylbenzyl alcohol is another secondary alcohol that could be successfully oxidized (acetophenone yield reaches $85 \%$ after 5 h with a selectivity of $89 \%$, with the catalyst UiO-19).

\section{Conclusion.}

The zirconium terephthalate UiO-66 was shown to efficiently catalyze the oxidation of primary alcohol (benzyl alcohol) and the secondary alcohol (2-methylbenzyl and 2-hexanol) under mild reaction temperatures $\left(\mathrm{T}=40^{\circ} \mathrm{C}\right)$. Catalytically active sites were demonstrated to be the under-coordinated zirconium $\left(\mathrm{Zr}_{\mathrm{UC}}\right)$ pairs located either at the inorganic cornerstones as structure defects owing to missing organic linkers or onto the external crystal surfaces. The role of these two types of sites was evidenced by systematically and independently modulating either the density of missing linkers within the structure or the external surface of the UiO-66 crystals, respectively. Notably, a particularly active catalyst was obtained by synthesizing defective UiO-66 crystals of very small size combining a large amount of B$\mathrm{Zr}_{\mathrm{UC}}$ sites (within the bulk) with numerous $\mathrm{ES} \mathrm{Zr}_{\mathrm{UC}}$ sites (on the external surface). The occurrence of $\mathrm{Zr}_{\mathrm{UC}}$ sites at both locations in the crystals was confirmed by vibrational spectroscopy of CO probe molecules and solid-state ${ }^{1} \mathrm{H}$ NMR experiments. A correlation between the existence of Lewis acid sites and the occurrence of a NMR signal at negative chemical shift (or close to $0 \mathrm{ppm}$ ) was made, allowing to attribute this latter signal to the protons of terminal $\mu_{1}-\mathrm{OH}$ groups that cap the $\mathrm{ZrUC}$ sites in the presence of moisture. These protons exhibit slightly different chemical shift depending if they are associated to $\mathrm{B}-\mathrm{Zr}_{\mathrm{UC}}$ or $\mathrm{ES}-\mathrm{Zr}$ sites.

A mechanism relying on the hydride transfer from the alcohol to the tert-butyl hydroperoxide is also proposed. Beside demonstrating the importance of combining B- and ES- $\mathrm{Zr}_{\mathrm{UC}}$ sites, this study suggests that zirconium-based MOFs possessing unsaturated zirconium sites can activate alkyl hydroperoxide that functions as hydride acceptor to oxidize alcohols, as suggested by Krohn et al. with zirconium alkoxides as catalysts. ${ }^{4}$

\section{Conflicts of interest}

The authors declare no conflict of interest.

\section{Acknowledgements}

The authors sincerely acknowledge Sandra Casale from LRS (Laboratoire de Réactivité de surface) for her contributions regarding transmission electron microscopy.

\section{References}

(1) X. Ye, M. D. Johnson, T. Diao, M. H. Yates, and S. S. Stahl, Green Chem., 2010, 12, 1180 1186.

(2) S. Caron, R. W. Dugger, S. G. Ruggeri, J. A. Ragan, and D. H. B. Ripin, Chem. Rev., 2006, 106, 2943-2989. 
(3) M. Boronat, A. Corma, and M. Renz, J. Phys. Chem. B., 2006, 110, 21168-21174.

(4) K. Krohn, I. Vinke, and H. Adam, J. Org. Chem., 1996, 61, 1467-1472.

(5) C. Djerassi, Organic Reactions, John Wiley \& Sons, Inc., Hoboken, NJ, USA, 2011, 207-272.

(6) K. Kaneda, Y. Kawanishi, and S. Teranishi, Chem. Lett., 1984, 9, 1481-1482.

(7) M. V. Gulenova, L. P. Stepovik, and V. K. Cherkasov, Russ. J. Gen. Chem., 2006, 76, 980 988.

(8) F. Vermoortele, R. Ameloot, A. Vimont, C. Serre, and D. De Vos, Chem. Commun., 2011, 47, $1521-1523$.

(9) U. S. F. Arrozi, H. W. Wijaya, A. Patah, Y. Permana. Applied Catalysis., 2015, 506, 77-84.

(10) J. Kim, S. N. Kim, H. G. Jang, G. Seo, W. S. Ahn, Applied Catalysis A., 2013, 453, 175-180.

(11) J. Hajek, B. Bueken, M. Waroquier, D. De Vos, and V. Van Speybroeck, ChemCatChem., 2017, 9, 2203-2210.

(12) C. V. McGuire and R. S. Forgan, ChemComm., 2015, 51, 5199-5217.

(13) C. Chizallet, S. Lazare, D. Bazer-Bachi, F. Bonnier, V. Lecocq, E. Soyer, A. A. Quoineaud, and N. Bats, J. Am. Chem. Soc., 2010, 132, 12365-12377.

(14) G. C. Shearer, S. Chavan, J. Ethiraj, J. G. Vitillo, S. Svelle, U. Olsbye, C. Lamberti, S. Bordiga, and K. P. Lillerud, Chem. Mater., 2014, 26, 4068-4071.

(15) H. Wu, Y. Chua, S. V. Krungleviciute, M. Tyagi, P. Chen, T. Yildirim, and W. Zhou, J. Am. Chem. Soc., 2013, 135, 10525-10532.

(16) G. C. Shearer, S. Chavan, S. Bordiga, S. Svelle, U. Olsbye, and K. P. Lillerud, Chem. Mater., 2016, 28, 3749-3761.

(17) L. Liu, Z. Chen, J. Wang, D. Zhang, Y. Zhu, S. Ling, K. W. Huang, Y. Belmabkhout, K. Adil, Y. Zhang, B. Slater, M. Eddaoudi, and Y. Han, Nat. Chem., 2019, 11, 622-628.

(18) B. Bueken, N. Van Velthoven, T. Willhammar, T. Stassin, I. Stassen, D. A. Keen, G. V. Baron, J. F. M. Denayer, R. Ameloot, S. Bals, D. De Vos, and T. D. Bennett, Chem. Sci., 2017, 8, 3939-3948.

(19) R. Baran, F. Averseng, D. Wierzbicki, K. Chalupka, J. M. Krafft, T. Grzybek, and S. Dzwigaj, Appl. Catal. B., 2016, 523, 332-342.

(20) D. M. Driscoll, D. Troya, P. M. Usov, A. J. Maynes, A. J. Morris, and J. R. Morris, J. Phys. Chem. C., 2018, 122, 14582-14589.

(21) D. M. Driscoll, D. Troya, P. M. Usov, A. J. Maynes, A. J. Morris, and J. R. Morris, Phys. Chem. Chem. Phys., 2019, 21, 5078-5085.

(22) L. Zamirri, S. Casassa, A. Rimola, M. Segado-Centellas, C. Ceccarelli, and P. Ugliengo, Mon. Not. R. Astron. Soc., 2018, 480, 1427-1444.

(23) L. Valenzano, B. Civalleri, S. Chavan, S. Bordiga, M. H. Nilsen, S. Jakobsen, K. P. Lillerud, and C. Lamberti, Chem. Mater., 2011, 23, 1700-1718.

(24) S. Devautour-Vinot, G. Maurin, C. Serre, P. Horcajada, D. Paula da Cunha, V. Guillerm, E. de Souza Costa, F. Taulelle, and C. Martineau, Chem. Mater., 2012, 24, 2168-2177.

(25) C. A. Trickett, T. M. Osborn Popp, J. Su, C. Yan, J. Weisberg, A. Huq, P. Urban, J. Jiang, M. J. Kalmutzki, Q. Liu, J. Baek, M. P. Head-Gordon, G. A. Somorjai, J. A. Reimer, and O. M. Yaghi, Nat. Chem., 2019, 11, 170-176.

(26) M. Vandichel, J. Hajek, A. Ghysels, A. De Vos, M. Waroquier, and V. Van Speybroeck, CrystEngComm., 2016, 18, 7056-7069.

(27) M. C. Lawrence, C. Schneider, and M. J. Katz, Chem. Commun., 2016, 52, 4971-4974.

(28) F. Vermoortele, B. Bueken, G. Le Bars, B. Van De Voorde, M. Vandichel, K. Houthoofd, A. Vimont, M. Daturi, M. Waroquier, V. Van Speybroeck, C. Kirschhock, and D. E. De Vos, J. Am. Chem. Soc., 2013, 135, 11465-11468.

(29) S. Fujisawa, Y. Kadoma, and I. Yokoe, Chem. Phys. Lipids., 2004, 130, 189-195. 